\title{
Testing, simulation and design of cold-formed stainless steel CHS columns
}

\author{
Craig Buchanan ${ }^{\mathrm{a}, *}$, Esther Real ${ }^{\mathrm{b}}$, Leroy Gardner ${ }^{\mathrm{a}}$ \\ ${ }^{a}$ Department of Civil and Environmental Engineering, Imperial College London, London, UK \\ ${ }^{b}$ Department of Construction Engineering, Universitat Politècnica de Catalunya, Barcelona, Spain
}

\begin{abstract}
Stainless steel tubular members are employed in a range of load-bearing applications due to their strength, durability and aesthetic appeal. From the limited existing test data on stainless steel circular hollow sections (CHS) columns it has been observed that the current Eurocode 3 provisions can be unconservative in their capacity predictions. A comprehensive experimental programme has therefore been undertaken to provide benchmark data to validate numerical models and underpin the development of revised buckling curves; in total 17 austenitic, 9 duplex and 11 ferritic stainless steel CHS column buckling tests and 10 stub column tests have been carried out. Five different cross-section sizes (covering class 1 to class 4 sections) and a wide range of member slendernesses have been examined. The experiments were initially replicated using finite element (FE) simulations; the validated FE models were then used to generate 450 additional column buckling data points. On the basis of the experimental and numerical results, new design recommendations have been made for cold-formed stainless steel CHS columns and statistically validated according to EN 1990 (2005).
\end{abstract}

Keywords: circular hollow sections, design methods, experiments, flexural buckling, stainless steel, testing

\section{Introduction}

Circular hollow sections (CHS) are a common form of structural element that have been used for almost 200 years [2]. They are popular with architects and structural engineers due to their aesthetics and numerous benefits over other open and closed cross-sections, such as a 5 high torsional resistance, the ability to be filled with concrete to act as a composite member, reduced drag loading in a fluid, good bi-axial bending resistance and reduced maintenance requirements with a smaller exposed external area. CHS are commonly used as compression members, with iconic examples including the main cantilever compression members of the Forth Bridge in Scotland, constructed in 1890, and many of the components of the London

\footnotetext{
*Corresponding author

Email address: craig.buchanan08@imperial.ac.uk (Craig Buchanan)
} 
Eye, opened in 2000. Stainless steel has been available as a material since 1912-13, having been developed separately in the UK and Germany, with the name applied to iron alloys with corrosion resisting properties and containing a minimum of $10.5 \%$ chromium [3] A thin chromium-rich oxide film forms on the surface in the presence of oxygen which provides the corrosion resistance [3]. Austenitic, duplex and ferritic are the most frequently used grades of stainless steel in construction, and their design is included in EN 1993-1-4 (2015). Austenitic grades are the most prevalent and have a typical chromium content of $17-18 \%$ and a nickel content of $8-11 \%$. Duplex grades offer generally higher corrosion resistance, good wear resistance and higher strength, but also have a greater initial cost with a typical chromium content of $22-23 \%$ and a nickel content of $4-5 \%$. Ferritic grades have a lower initial cost due to their reduced chromium and nickel content, typically $11-17 \%$ and $0-2.5 \%$ respectively, albeit at the expense of corrosion resistance [5].

EN 1993-1-4 (2015) provides design guidance for the flexural buckling capacity of stainless steel CHS members through a harmonised approach that is consistent with the design of carbon steel elements in EN 1993-1-1 (2014). Prior to the experiments reported in this paper, existing test results on stainless steel CHS elements in compression have been rather limited. Previous test data have comprised predominantly austenitic stainless steel stub column results from Rasmussen and Hancock [7], Talja [8], Burgan et al. [9], Rasmussen [10], Young and Hartono [11], Kuwamura [12], Gardner and Nethercot [13], Lam and Gardner [14, Uy et al. [15] and Zhao et al. [16] and a small number of longer member results from Rasmussen and Hancock [7], Talja [8], Burgan et al. [9], Young and Hartono [11] and Zhao et al. [17]. There have also been a limited number of duplex stainless steel stub column tests by Bardi and Kyriakides [18], Paquette and Kyriakides [19] and Lam and Gardner [14] and ferritic stainless steel stub column tests by Stangenberg [20], but no existing test results on longer columns of either duplex or ferritic grades. It has been previously observed that many of the existing data points lie below the current EN 1993-1-4 (2015) flexural buckling curve [11, 21 26]. The primary reason for this is that the buckling curve was calibrated using predominantly cold-formed square hollow section (SHS) and rectangular hollow section (RHS) column buckling test results [21], due to a lack of stainless steel CHS experimental data at the time that the standard was produced. Cold-formed SHS and RHS benefit from increased material strength in the heavily work-hardened corner regions [27], and hence a buckling curve calibrated to experimental data on cold-formed SHS and RHS may be inappropriate for CHS.

It is apparent that there is a requirement firstly to expand the existing flexural buckling dataset on stainless steel CHS and to evaluate existing proposals for an updated buckling curve and secondly to put forward revised design recommendations; this is the focus of the work presented in this paper. 


\section{Experimental testing programme}

\subsection{General overview}

The experimental programme consisted of material property tests, stub column tests and concentrically loaded long column tests. The test specimens covered a wide range of local slenderness values spanning all four classes of cross-section [4], a wide range of global slenderness values, with effective column lengths varying from $300 \mathrm{~mm}$ to $3080 \mathrm{~mm}$, and included all three main types of stainless steel used in construction. The experimental programme was split between Imperial College London (ICL) and Universitat Politècnica de Catalunya (UPC). Five cross-section sizes were tested. The column tests for the two austenitic (A) cross-sections, $106 \times 3 \mathrm{CHS}$ (class 1/2) and $104 \times 2 \mathrm{CHS}$ (class 3/4), and the duplex (D) cross-section, $88.9 \times 2.6 \mathrm{CHS}$ (class $3 / 4$ ), were carried out at ICL, along with the tensile coupon testing. The CHS tested at ICL were all close to the class 2 or class 3 limit, and hence depending upon the measured dimensions could be one of two cross-section classes. The column tests on the two ferritic (F) cross-sections, $80 \times 1.5 \mathrm{CHS}$ (class 3 ) and 101.6×1.5 CHS (class 4), were undertaken at UPC. The austenitic and duplex tubes were cut at ICL using a band saw, with wooden cylinders inserted to reduce clamping deformations, while the ferritic specimens were laser cut by the supplier. The chemical composition of the specimens, as stated in the mill certificates, are provided in Table 1. The CHS were all produced by cold-forming and longitudinal welding. Prior to cutting it was noted that the $104 \times 2$ tubes came from two different sources, both from the country markings (Sweden and Finland) on the tubes and the external finish around the weld, although there was no distinction on the mill certificate. The specimen notation is illustrated by the following example: $104 \times 2-400-\mathrm{F}$ is a $104 \times 2$ cross-section with a $400 \mathrm{~mm}$ nominal length (or effective length) with ' $\mathrm{F}$ ' indicating fixed end conditions, whereas a specimen with a ' $\mathrm{P}$ ' indicates pinned end conditions; a specimen ending with ' $R$ ' denotes a repeat specimen.

\subsection{Material properties}

Tensile coupon tests were undertaken to determine the basic material stress-strain properties of the tubes. The tensile coupon tests were undertaken in compliance with EN ISO 68921 (2009) using an Instron 8802 testing machine, with a data recording frequency of $1 \mathrm{~Hz}$. Two tensile coupons were prepared from each cross-section, with the coupons having the traditional dog-bone shape and cut on opposite sides at $90^{\circ}$ to the weld position, and had the standard gauge lengths marked. The instrumentation consisted of two mid-height electrical resistance strain gauges to measure strains up to the material $0.2 \%$ proof stress, a video extensometer that measured the strains beyond this point and a load cell to measure the applied tensile load. As recommended in EN ISO 6892-1 (2009) two crosshead separation rates were used before and post yield, depending upon the parallel length of the necked region, with a gradual ramp between them. Filler material was applied to the concave face of the coupons to prevent the machine grips from deforming the ends of the coupons and inducing bending within the coupon due to an eccentrically applied tensile force. The cross-sectional area of the necked region of the coupons was determined using AutoCAD from the average measured coupon 


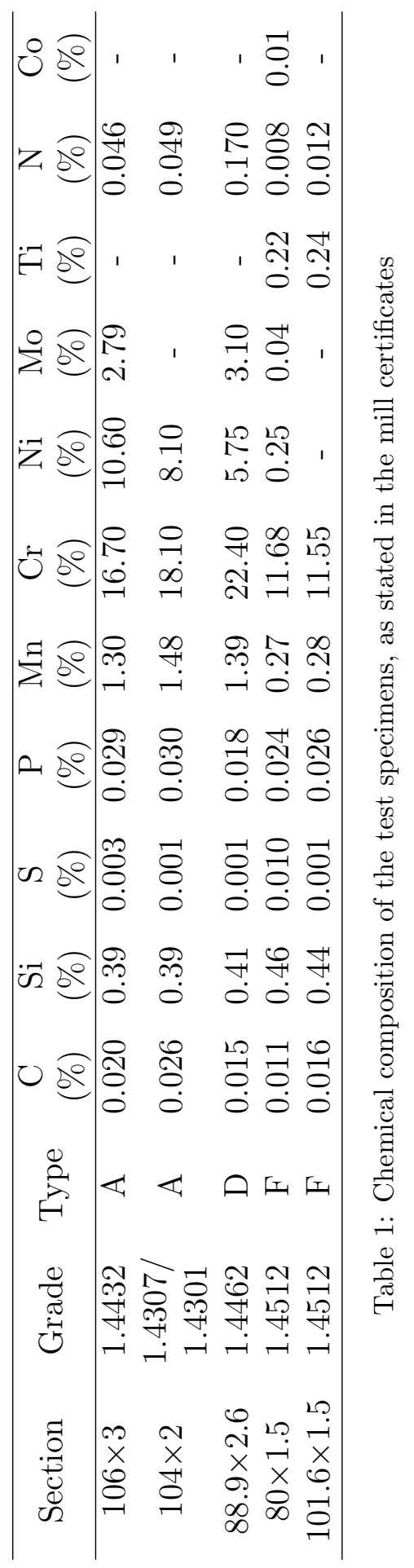




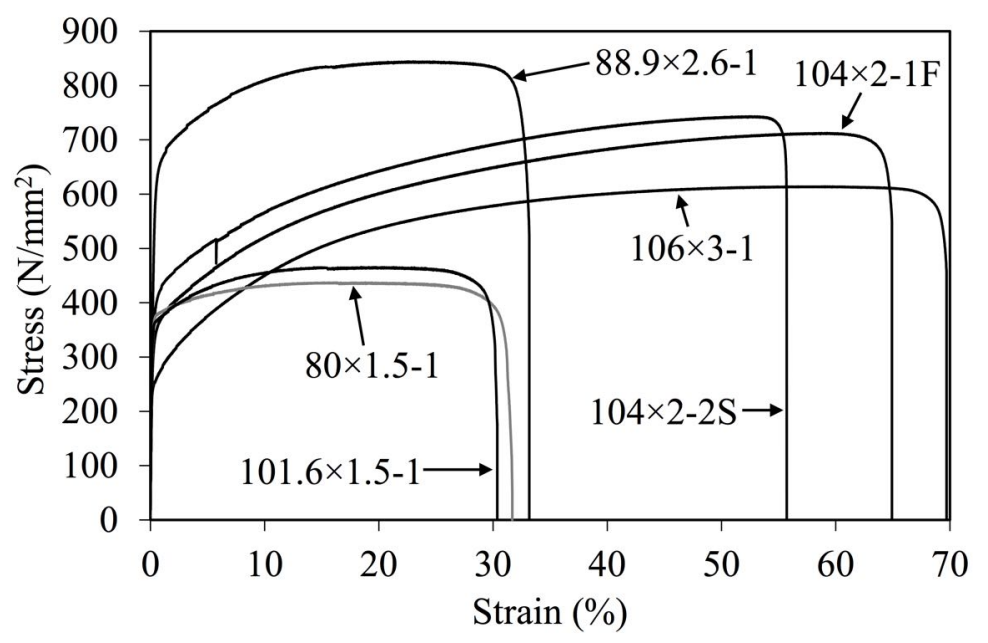

Figure 1: Typical tensile coupon stress-strain curves

dimensions. Typical stress-strain curves from the tensile coupons are shown in Figure 1, while the Young's modulus $E, 0.2 \%$ proof stress $\sigma_{0.2}, 1.0 \%$ proof stress $\sigma_{1.0}$, ultimate tensile stress $\sigma_{\mathrm{u}}$, strain at the ultimate tensile stress $\varepsilon_{\mathrm{u}}$, fracture strain over the marked gauge length $\varepsilon_{\mathrm{f}}$, the Ramberg-Osgood parameter $n$ [29] and the extended parameters $n_{0.2,1.0}^{\prime}$ and $n_{0.2, \mathrm{u}}^{\prime}$ 30 32 determined from the coupon tests are reported in Table 2. The Ramberg-Osgood and extended parameters were determined using weighted total least squares regression that is independent of the distribution of the data points. As noted previously, the $104 \times 2$ tubes came from Sweden and Finland and hence the relevant coupons are labelled with an 'S' and ' $\mathrm{F}$ ' respectively, with the difference apparent from Table 2 with the ' $\mathrm{S}$ ' coupons having a higher Young's modulus $E, 0.2 \%$ proof stress $\sigma_{0.2}$ and ultimate tensile stress $\sigma_{\mathrm{u}}$ than the 'F' coupons.

\subsection{Geometric properties}

The geometric properties of the CHS specimens were measured before testing. Outer diameter measurements were taken at three equally spaced longitudinal locations for the short stub columns and shorter pin-ended columns $(L<400 \mathrm{~mm})$ and at five equally spaced longitudinal locations for the longer columns. At each location the outer diameter was recorded in four evenly distributed orientations (at $45^{\circ}$ intervals) with callipers, allowing the average outer diameter $D$ of the specimen to be calculated along with its 'out-of-roundness' as defined in EN 10219-2 (2006). Prior to cutting the individual austenitic and duplex specimens from the delivered tubes, the lengths of CHS tube with the least 'out-of-roundness' were identified and the required specimens were cut from these lengths. The maximum 'out-of-roundness' $O$ of the non-repeat specimens was $2.0 \%$, satisfying the limit of $O \leq 2.0 \%$, although the $106 \times 3-750-\mathrm{PR}$ repeat specimen had $O=2.4 \%$. The average wall thickness $t$ was determined from measurements of the wall thickness at the ends of the tubes at eight equally spaced locations (at $45^{\circ}$ intervals) around the circumference, at a distance not less than $2 t$ from the weld location in accordance with EN 10219-2 (2006). The ferritic pin-ended columns 


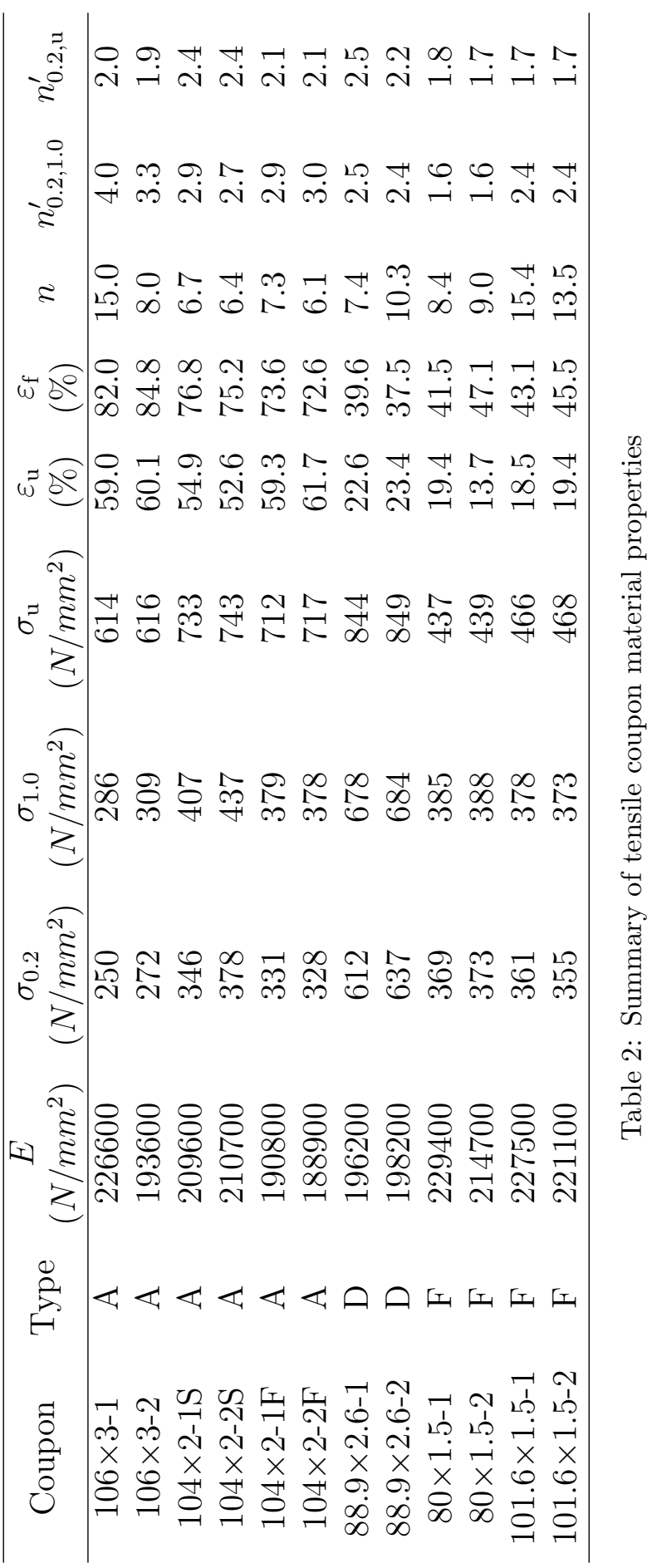


had $10 \mathrm{~mm}$ thick end plates welded to each end to allow mechanical attachment to the knife edges. The wall thicknesses of the pin-ended ferritic columns could not be measured due to the welded end plates, although the variation around the ferritic stub columns was small $(<4.5 \%,<0.06 \mathrm{~mm})$ and the average wall thickness $t$ for the ferritic stub columns is used for the pin-ended columns. The average specimen length $L$, which for the pin-ended members includes the additional length from the knife edges, was calculated by averaging the specimen length from four separate measurements taken at $90^{\circ}$ locations around the circumference. The mid-length global imperfection amplitudes were recorded by measuring the deviation from a flat plane linking the two ends of the specimens. For the shorter specimens the deviation was measured using the bottom of a spirit level and feeler gauges, whereas for the longer specimens studied at ICL a self levelling laser and steel rule were used and at UPC an aluminium extrusion was placed over the end plates and the deviation measured using callipers. The imperfection measurements were made on the two faces parallel to the knife-edge axis (i.e. to obtain the imperfection in the direction of buckling) for the pin-ended specimens. The average geometric properties of the specimens are provided in Table 3 for the stub columns and Tables 5 to 9 for the pin-ended columns.

The weld position for the UPC specimens was fixed relative to the axis of buckling, with the weld orientated to be on the least compressed face. The 'out-of-roundness' of the ICL specimens were generally close to the $2.0 \%$ limit, and this was considered to have a greater effect on the buckling capacity of the member than the weld orientation. For the ICL tests the specimens were therefore orientated with the smallest average diameter to be perpendicular to the knife edge axis (i.e. the orientation with the minimum second moment of area $I$ in the direction of buckling), which had the consequence that the weld position rotated between specimens. Neither of the two effects are considered to have had a significant influence on the results.

\subsection{Stub column tests}

Stub column tests were undertaken to determine the cross-sectional load carrying capacity under pure compression and also to ascertain compressive material properties for use later in the assessment of buckling curves. The stub column lengths were chosen to be sufficiently long to include a representative distribution of local imperfections and residual stresses, but short enough to preclude global buckling [34].

The test setup at ICL for the austenitic and duplex stub columns is shown in Figure 2 . An Instron $3500 \mathrm{kN}-\mathrm{SPL}$ testing machine was used with a proprietary in-house developed datalogger and software recording the various parameters at a recording frequency of $2 \mathrm{~Hz}$. The instrumentation consisted of three electrical resistance strain gauges equally spaced around the circumference at mid-height (with the weld located centrally between two strain gauges), three equally spaced potentiometers to measure the vertical movement of the top platen and a load cell within the machine to measure the applied load. 


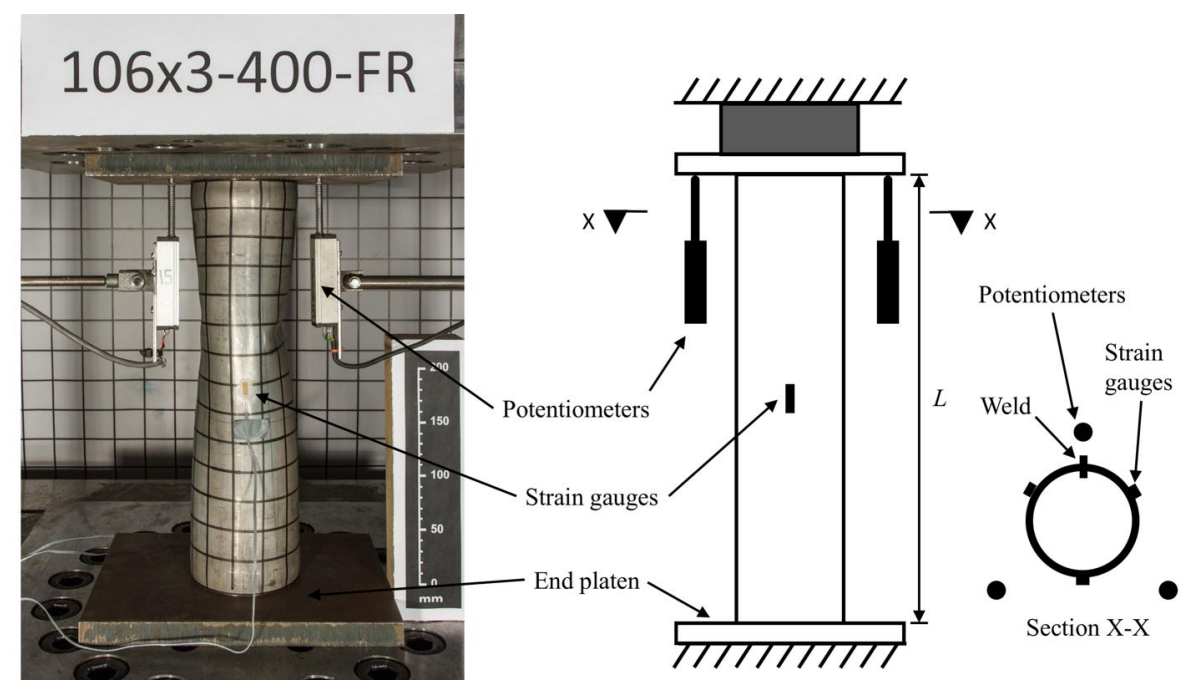

Figure 2: ICL stub column test setup

The test setup for the ferritic stub columns at UPC is shown in Figure 3. An Instron 8805 testing machine was used with a HBM MGCplus datalogger and Catman software recording at a frequency of $2 \mathrm{~Hz}$. A spherical head was utilised to ensure full contact with the top of the stub columns, with the head free to move initially but locked at a load of $5 \mathrm{kN}$, ensuring full contact of both ends of the stub column with the testing machine. The instrumentation consisted of three electrical resistance strain gauges equally spaced around the circumference at mid-height (with the weld again located centrally between two strain gauges), three equally spaced linear variable displacement transducers (LVDTs) to measure the movement of the top platen, and a load cell within the testing machine to measure the compressive load.

The top platen moved at a displacement rate of $0.2 \mathrm{~mm} / \mathrm{min}$ for the austenitic and ferritic stub columns, and at a slightly slower displacement rate of $0.15 \mathrm{~mm} / \mathrm{min}$ for the shorter duplex $88.9 \times 2.6$ CHS stub columns, in line with previous CHS stub column tests by Stangenberg [20] and Zhao et al. [16] and were continued beyond the ultimate load to observe the initial unloading behaviour. Two stub columns were tested for each cross-section, with one from each country of origin for the $104 \times 2$ CHS stub columns. Square grids were painted onto the specimens prior to testing using a lathe to allow for visualisation of the deformations.

The average outer diameter $D$, wall thickness $t$, specimen length $L$, initial imperfection amplitude $\omega_{0}$, ultimate axial load $N_{\mathrm{u}}$, end shortening at the ultimate load $\delta_{\mathrm{u}}$, accounting for the deformation of the end platens [35], and ultimate load normalised by the yield load $N_{\mathrm{u}} / A \sigma_{0.2}$ (where $\sigma_{0.2}$ is the average tensile $0.2 \%$ proof stress) are reported in Table 3. The country of origin for the $104 \times 2$ CHS is also listed, with FIN and SWE being Finland and Sweden respectively. The compressive material properties derived from the stub column tests, that were deemed not to be influenced by local buckling since the average strains at the ultimate load were well in excess of those at the $0.2 \%$ proof stress $\left(E_{\mathrm{stub}}, \sigma_{0.2 \mathrm{stub}}\right.$, 


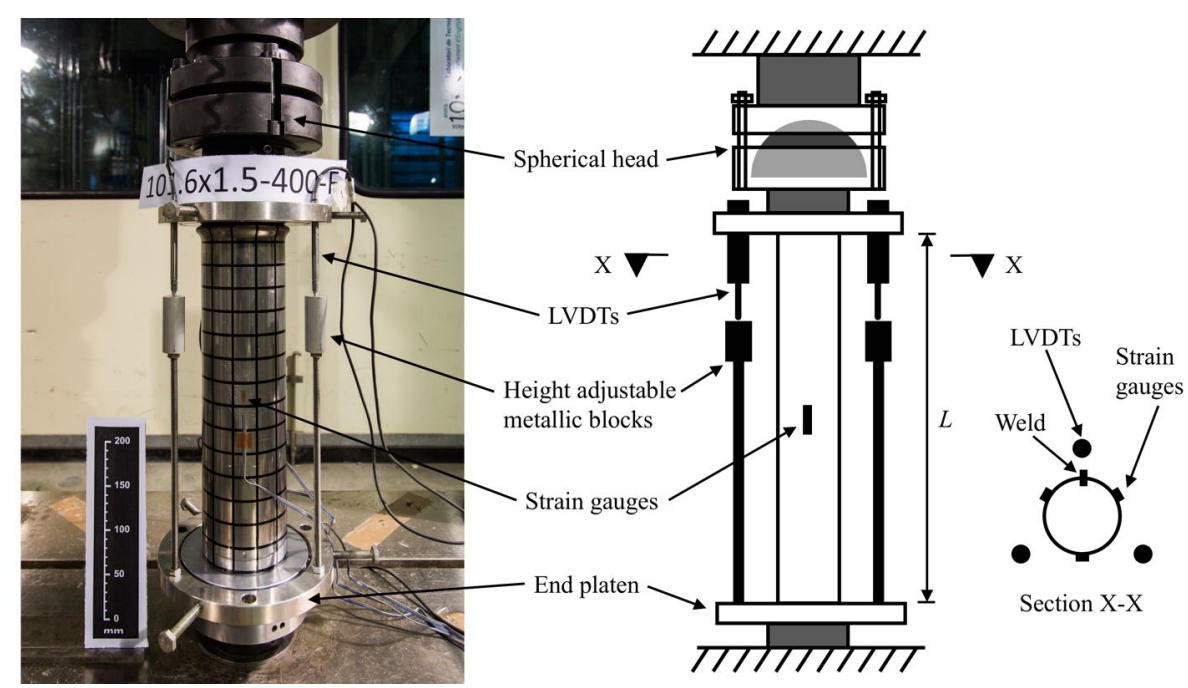

Figure 3: UPC stub column test setup

$\sigma_{1.0, \text { stub }}$ and $\left.n_{\text {stub }}\right)$, are listed in Table 4. The average tensile $0.2 \%$ proof stress normalised by the compressive stub column $0.2 \%$ proof stress $\sigma_{0.2} / \sigma_{0.2 \text { stub }}$ shows that the tensile and compressive properties are generally fairly consistent; the ratio $\sigma_{0.2} / \sigma_{0.2 \text {,stub }}$ has an average value very close to unity and reaches 0.88 and 1.10 at the extremes, though note that there is a degree of variation due to inherent experimental scatter for individual specimens. The stub column load-end shortening curves are shown in Figure 4. The load-end shortening curves show that the class $1106 \times 3$ cross-sections undergo significant strain hardening before failure. The $106 \times 3$ stub columns initially developed a slight 'elephant's foot' buckle but then buckled locally close to mid-height, as shown in Figure 2. The other stub columns all exhibited the classic 'elephant's foot' buckle at one end.

\subsection{Flexural buckling test setup}

The flexural buckling tests consisted of 17 austenitic, 9 duplex and 11 ferritic concentrically loaded, pin-ended column specimens with a wide range of local and global slendernesses. The austenitic tests supplemented the existing dataset [7-9, 11, 17]; the duplex and ferritic tests are the first flexural buckling tests on CHS with these stainless steel grades. The specimen lengths were chosen to provide a range of global slenderness $\bar{\lambda}$ values, with the maximum length dictated by the testing machines used. The global slenderness $\bar{\lambda}$ is calculated using Equations 1 and 2 depending on the cross-section classification,

$$
\begin{gathered}
\bar{\lambda}=\sqrt{\frac{A \sigma_{0.2} L^{2}}{\pi^{2} E I}} \text { for class } 1,2 \text { and } 3 \text { cross-sections } \\
\bar{\lambda}=\sqrt{\frac{A_{\mathrm{eff}} \sigma_{0.2} L^{2}}{\pi^{2} E I}} \text { for class } 4 \text { cross-sections }
\end{gathered}
$$



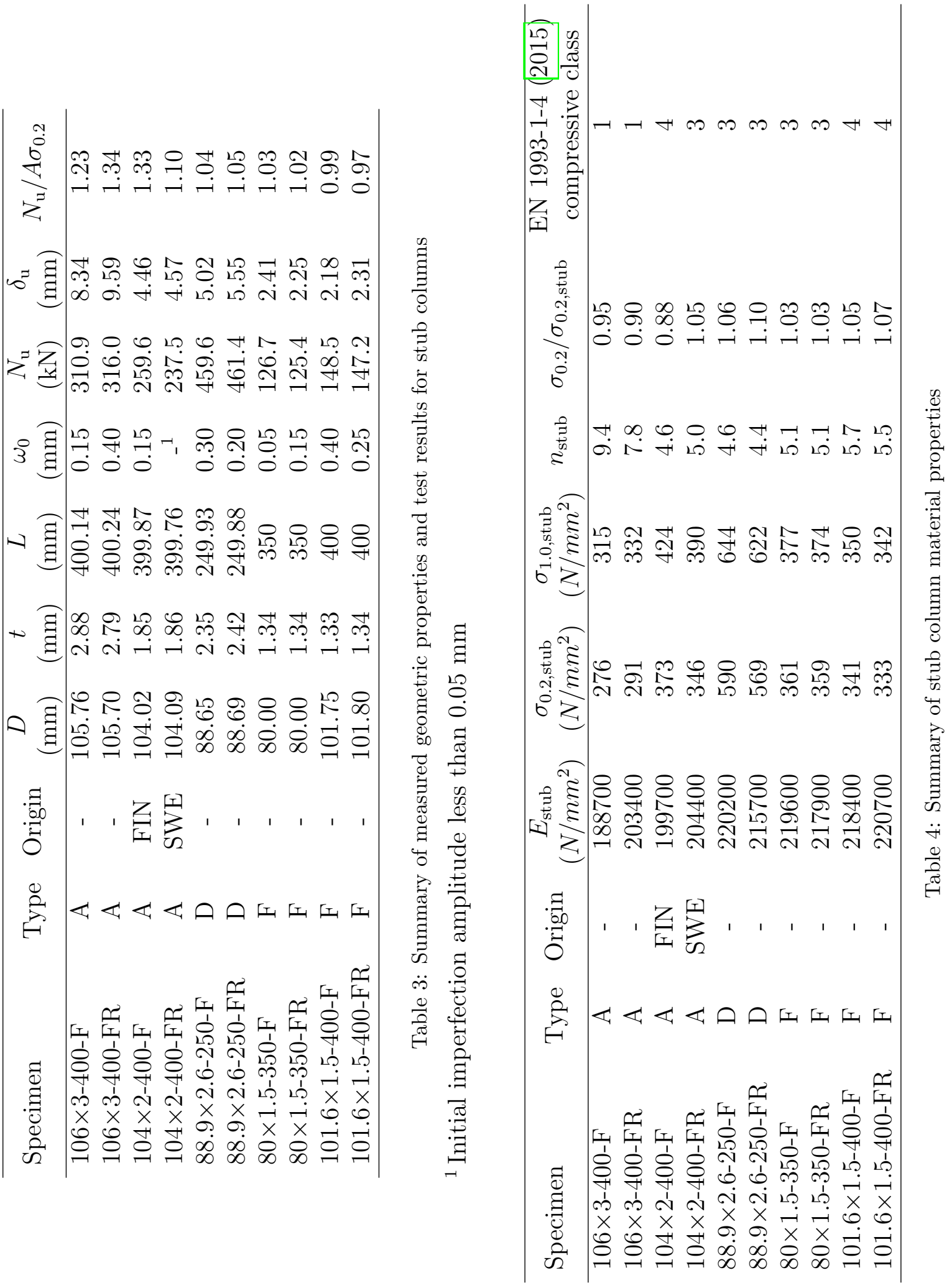


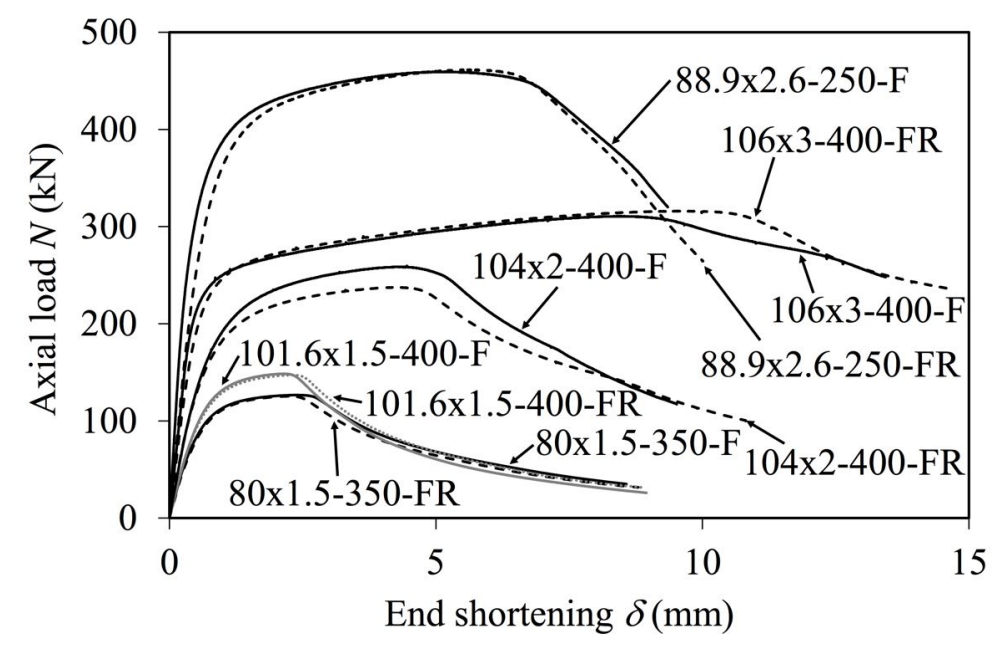

Figure 4: Stub column load-end shortening curves

where $A$ is the gross cross-sectional area, $A_{\text {eff }}$ is the effective cross-sectional area, $\sigma_{0.2}$ is the $0.2 \%$ proof stress, $E$ is the Young's modulus, $I$ is the second moment of area and $L$ is the effective length. The global slenderness $\bar{\lambda}$ values and EN 1993-1-4 (2015) compressive cross-section classes are reported in Tables 5 to 9. EN 1993-1-4 (2015) does not provide an expression for $A_{\text {eff }}$ for a CHS and therefore the design formula from BS 5950-1 (2000) has been used with updated EN 1993-1-4 (2015) compressive class 3 slenderness limits [37, 38], as reproduced in Equation 3 .

$$
A_{\text {eff }}=A\left[\left(\frac{90}{D / t}\right)\left(\frac{235}{\sigma_{0.2}} \frac{E}{210000}\right)\right]^{0.5}
$$

Three different experimental setups were utilised due to testing in different locations and certain setups having specimen length limitations. The Instron $2000 \mathrm{kN}-\mathrm{SPL}$ test setup used for the austenitic and duplex columns at ICL is shown in Figure 5. Two setups were used at UPC for the ferritic columns - specimens with $L \leq 1100 \mathrm{~mm}$ were tested using an Instron 8805 testing machine as shown in Figure 6, while the $1600 \mathrm{~mm}$ specimens were tested using an Ibertest MDA-700 setup as shown in Figure 7. The lengths $L$ reported for the pin-ended columns are the effective lengths and include the additional length from the knife edges, which were each $77 \mathrm{~mm}$ thick at ICL and $40 \mathrm{~mm}$ thick at UPC, and the $10 \mathrm{~mm}$ thick welded end plates at UPC.

A spherical head was again used at UPC with the Instron 8805 test setup as shown in Figure 6, to attain full contact with the welded end plates. Prior to testing, the spherical head was loosened and checked for freedom of movement; the specimen was then bolted in place and an installation load of $5 \mathrm{kN}$ was applied at which point the bolts were tightened, locking the spherical head in place, before removing the $5 \mathrm{kN}$ installation load. The spherical head could not be used with the Ibertest setup due to limited headroom and was not used 


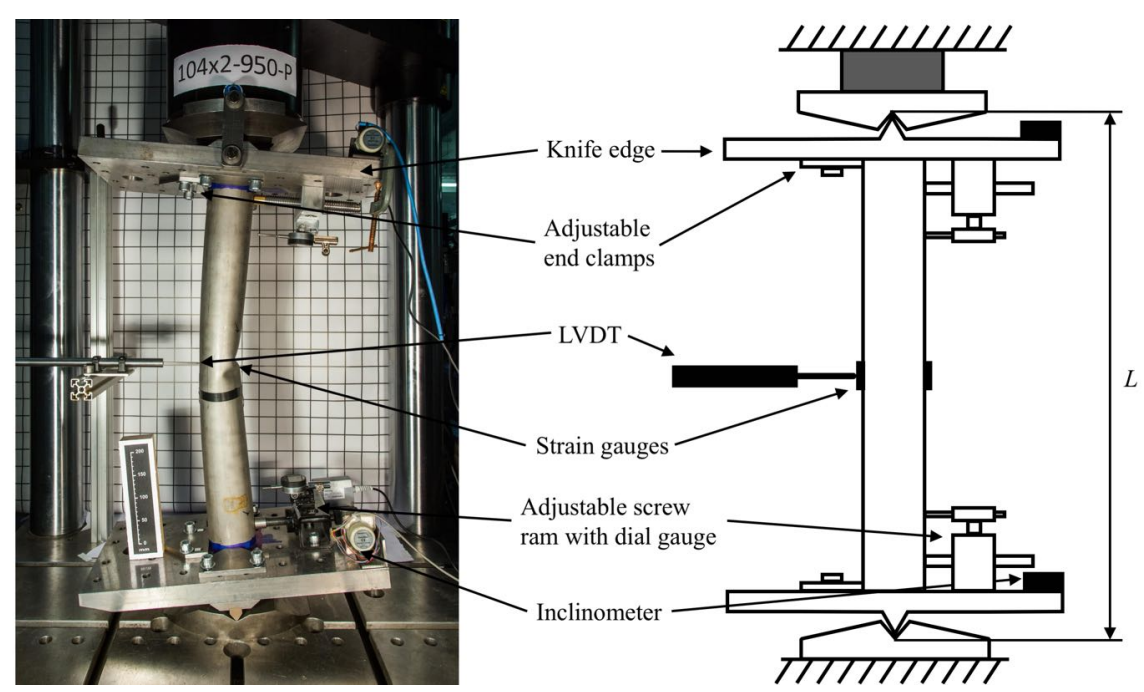

Figure 5: ICL Instron 2000kN-SPL pin-ended column test setup

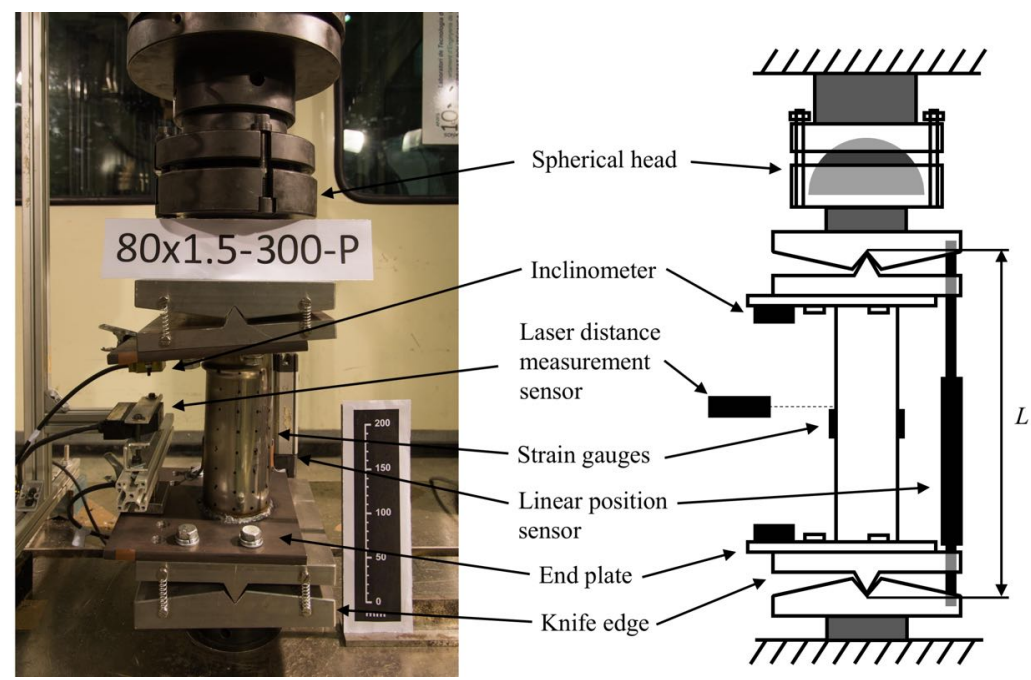

Figure 6: UPC Instron 8805 pin-ended short column test setup 


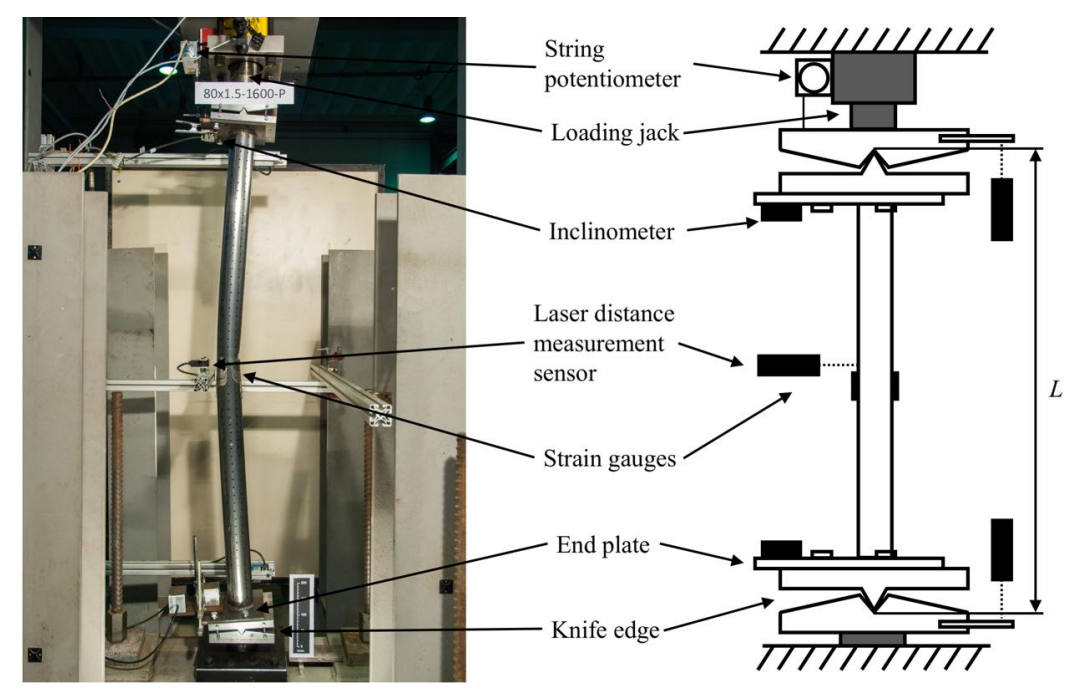

Figure 7: UPC Ibertest MDA-700 pin-ended long column test setup

with the ICL tests as the column ends were machined to be flat and parallel prior to testing.

A range of instrumentation was used throughout the testing programme depending upon the testing machines and setups. The end rotations were measured at both ends of the specimens using inclinometers. Two electrical resistance strain gauges were affixed onto opposite faces at mid-height to measure the maximum and minimum strains arising from the flexural buckling. The mid-height lateral deflection was measured at UPC with a laser distance measurement sensor and at ICL using a linear variable displacement transducer (LVDT). For the Instron testing machines the load was measured using a load cell within the testing machines, whereas for the Ibertest testing machine the applied load was calculated from the pressure within the loading jack. For the end shortening, the position of the top platen was measured using an internal LVDT for the Instron testing machines and in the Ibertest setup using a string potentiometer attached to and controlling the displacement of the loading jack. At UPC a second sensor was used to measure the end shortening for the Instron setup a linear position sensor was attached between the outer non-rotating female parts of the knife edges and for the Ibertest setup two additional laser measurement devices were similarly utilised. The parameters being measured were again recorded at $2 \mathrm{~Hz}$ using a HBM MGCplus datalogger and Catman software at UPC and a proprietary in-house developed datalogger and recording software at ICL. All of the tests were also filmed for later review.

\subsection{Global imperfection and applied eccentricity}

In line with Rasmussen and Hancock [7] a combined equivalent global imperfection and applied eccentricity of $L / 1000$ was applied to all of the specimens to simulate the typically assumed imperfections in real columns. The combined initial imperfection $\omega_{0}$ and eccentricity 
$e_{0}$ can be determined from Equation 4, [16, 39, 40],

$$
\omega_{0}+e_{0}=\frac{E I\left(\varepsilon_{\max }-\varepsilon_{\min }\right)}{D N}-\omega
$$

where $E$ is the Young's modulus, $I$ is the second moment of area, $N$ is the axial load, $D$ is the average outer diameter, $\omega$ is the mid-height lateral displacement and $\varepsilon_{\max }$ and $\varepsilon_{\min }$ are the maximum and minimum strains from the two extreme fibres of the cross-sections.

The eccentricity was calculated by placing the specimen in the centre of the knife edges and then loading at a displacement rate of $0.2 \mathrm{~mm} / \mathrm{min}$ to approximately $15 \%$ of the expected failure load $N_{\mathrm{u}}$, ensuring that the specimen remained elastic but had sufficient load to have strains and lateral displacement that could be reliably measured. Following on from the first check the specimen was then carefully moved across the knife edges to attain the $L / 1000$ eccentricity; at ICL, an adjustable screw ram with a dial gauge was used at both ends of the columns to allow very controlled small movements of the column ends in conjunction with monitoring the amount of mid-height movement with the LVDT. At UPC, the specimens were moved using a light tap from a hammer onto the end plates and careful monitoring of the mid-height movement using the laser distance sensor; the specimens could be moved laterally a small amount due to the end plates having oversized bolt holes. The specimen would then be loaded again to $15 \%$ of $N_{\mathrm{u}}$ and its position further adjusted until the target eccentricity was approximately attained. The calculated combined global imperfection and eccentricity $L /\left(\omega_{0}+e_{0}\right)$ from Equation 4 , along with the measured global imperfection $L / \omega_{0}$ are reported in Tables 5 to 9 . It should be noted that while this method was found to reflect the physical movement (movement in one direction would result in an increase of the calculated eccentricity in the same direction), it was observed to be very sensitive. There would be small variations in the average eccentricity depending on the displacement rate of the top platen, and even between runs there would be small differences without the specimen being moved or touched, which for the smallest eccentricities increased the error; this is reflected in Tables 5 to 9 . Once the required eccentricity was attained, a displacment rate of $0.2 \mathrm{~mm} / \mathrm{min}$ was used to load the specimens to their ultimate load, with the end of the test at UPC dictated by the maximum rotation of the knife edge (approximately $4^{\circ}$ ); the ICL tests were stopped at a similar maximum rotation.

\subsection{Flexural buckling test results}

The ultimate test loads $N_{\mathrm{u}}$ are reported in Tables 5 to 9 , along with the location of manufacture for the $104 \times 2$ specimens. The load versus mid-height lateral deflection curves are presented in Figures 8 to 12 . The $106 \times 3-750-\mathrm{P}$ specimen was repeated as it had a lower ultimate load than the shorter $106 \times 3-550-\mathrm{P}$ specimen, although the remaining $106 \times 3$ tube stock had an 'out-of-roundness' outside the $O \leq 2 \%$ limit in EN 10219-2 (2006) and the repeat test achieved a similar ultimate load to the original specimen. 

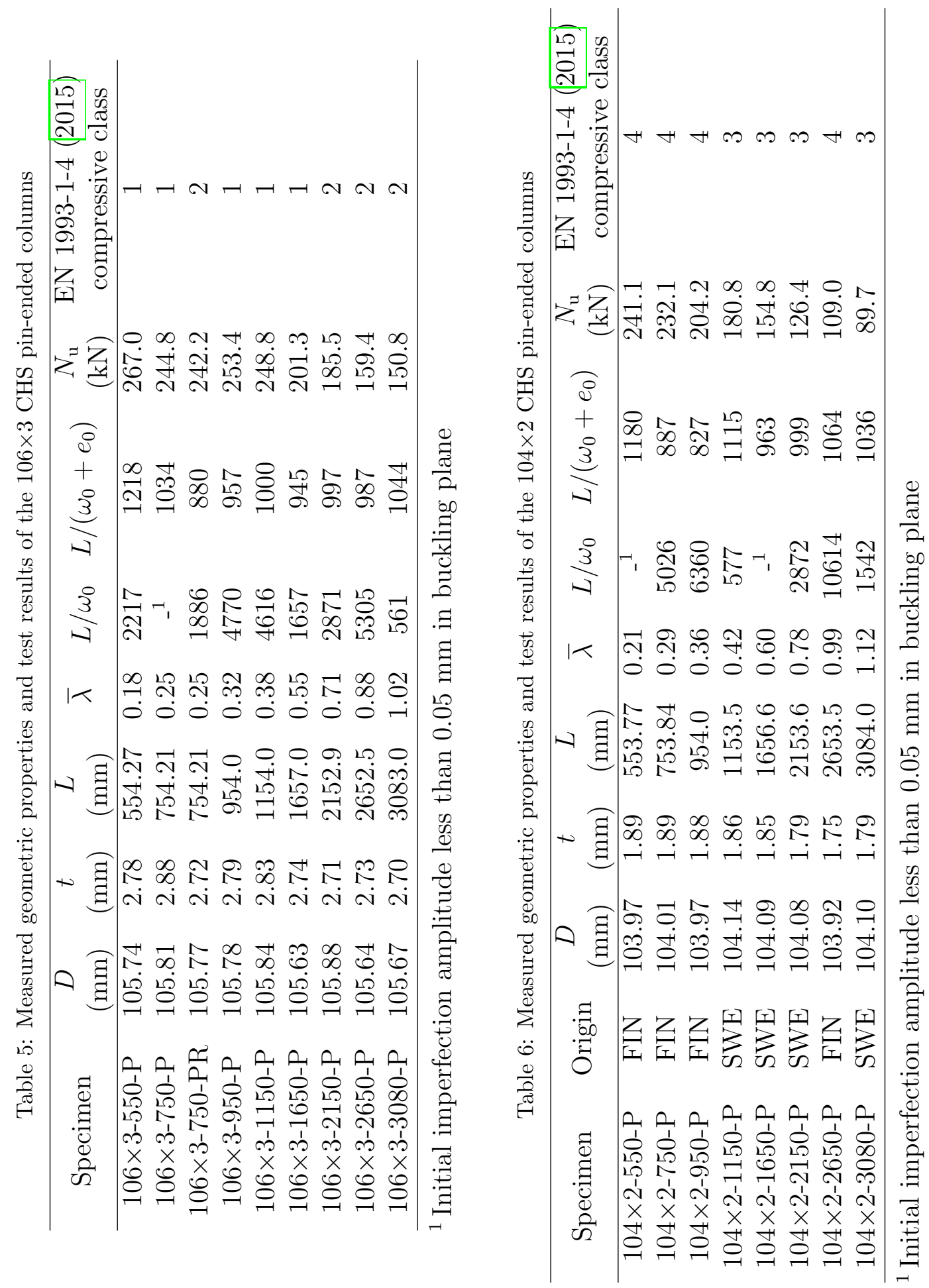


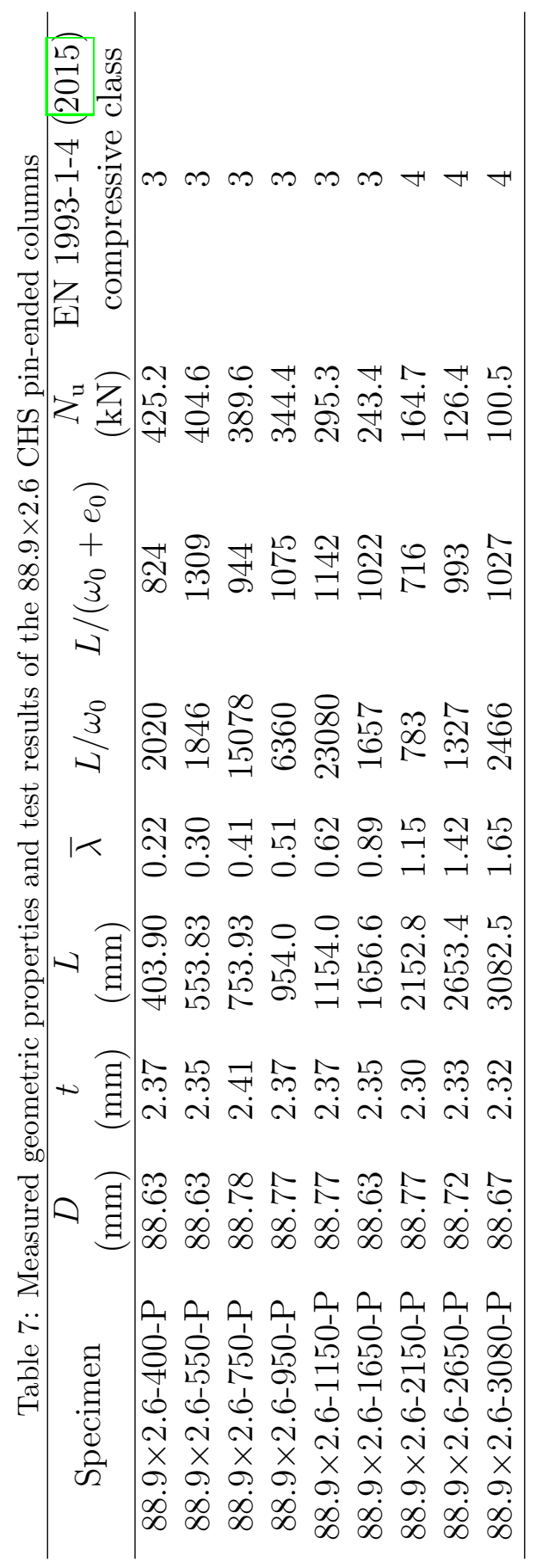



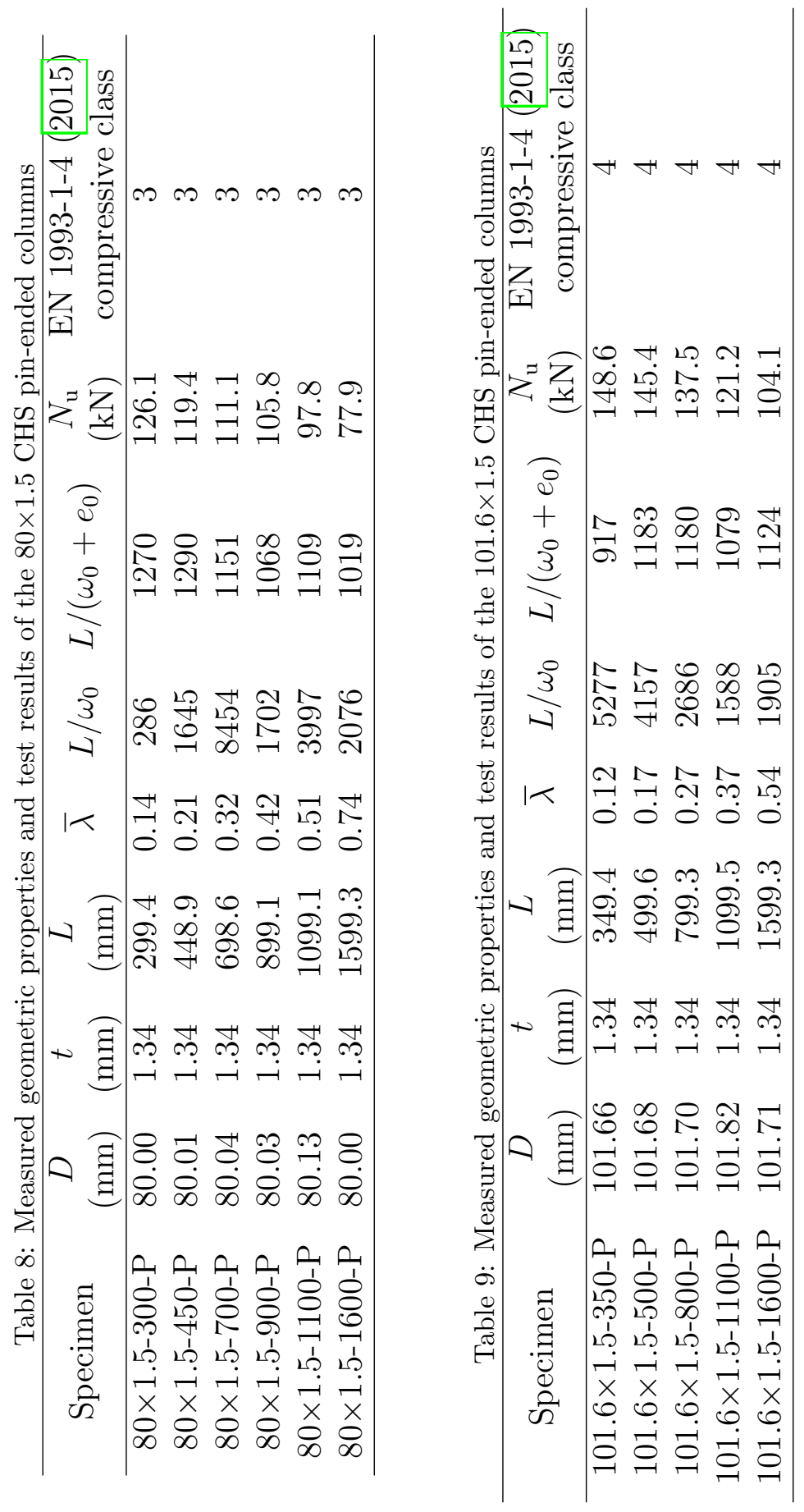


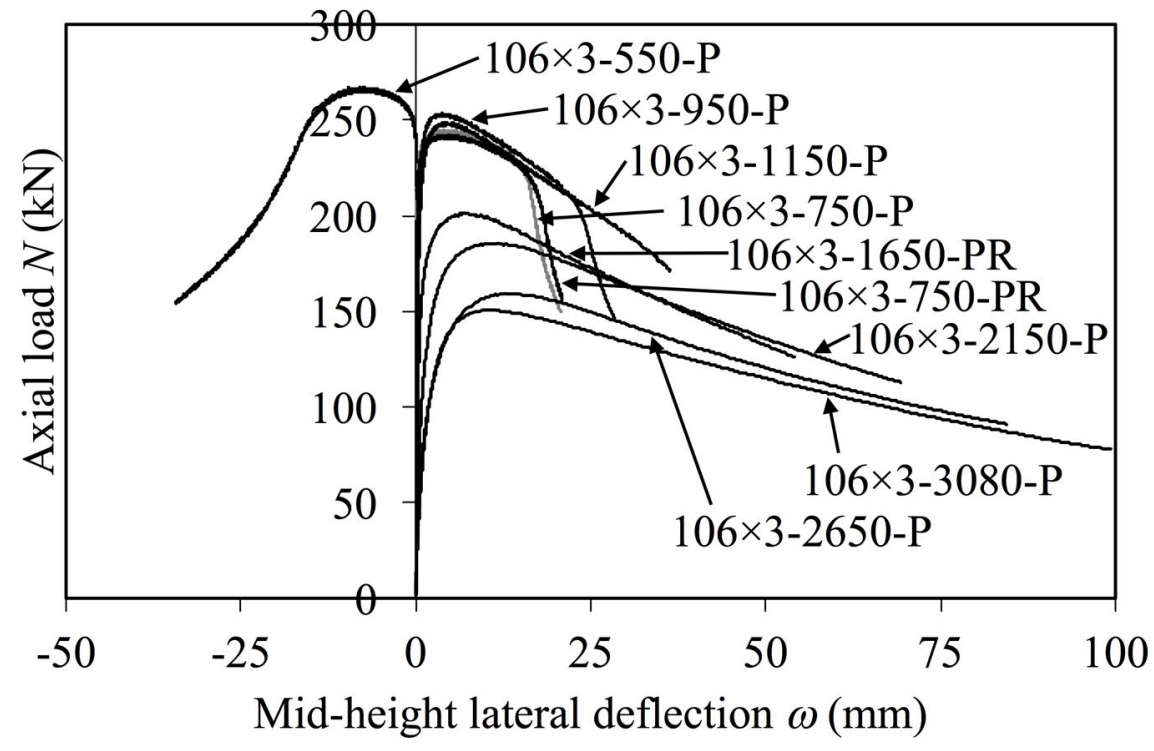

Figure 8: Experimental load versus mid-height lateral deflection curves for the $106 \times 3$ CHS specimens

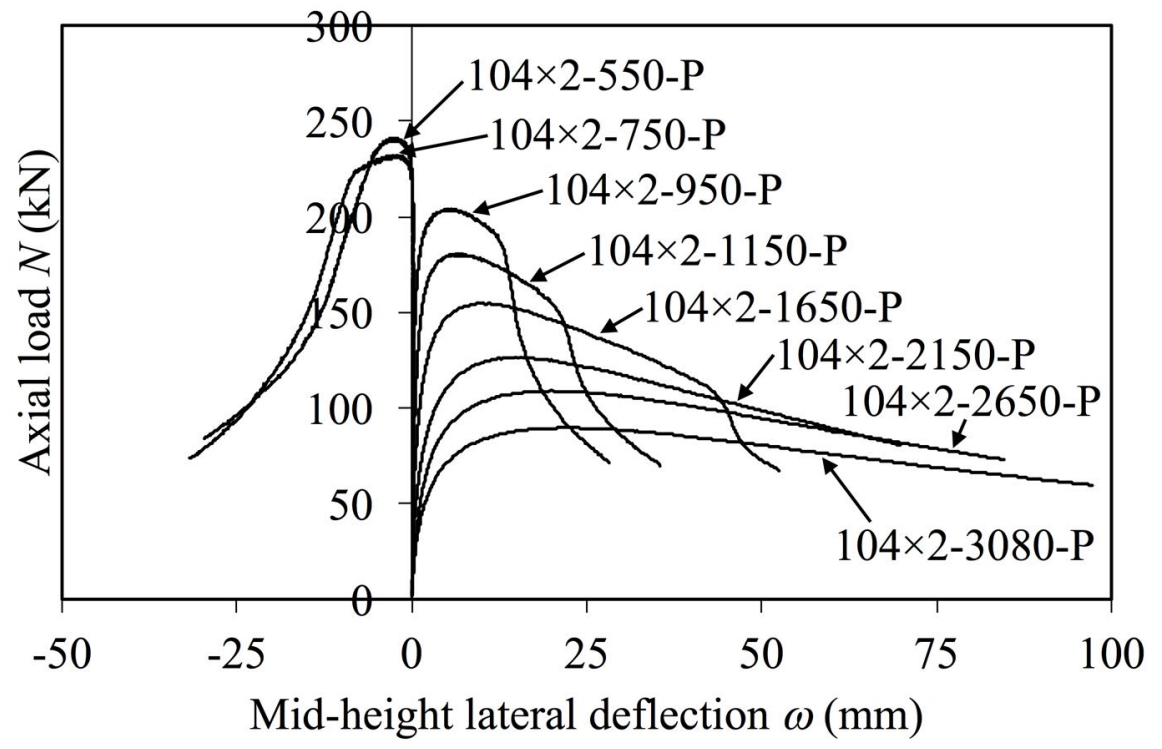

Figure 9: Experimental load versus mid-height lateral deflection curves for the $104 \times 2$ CHS specimens 


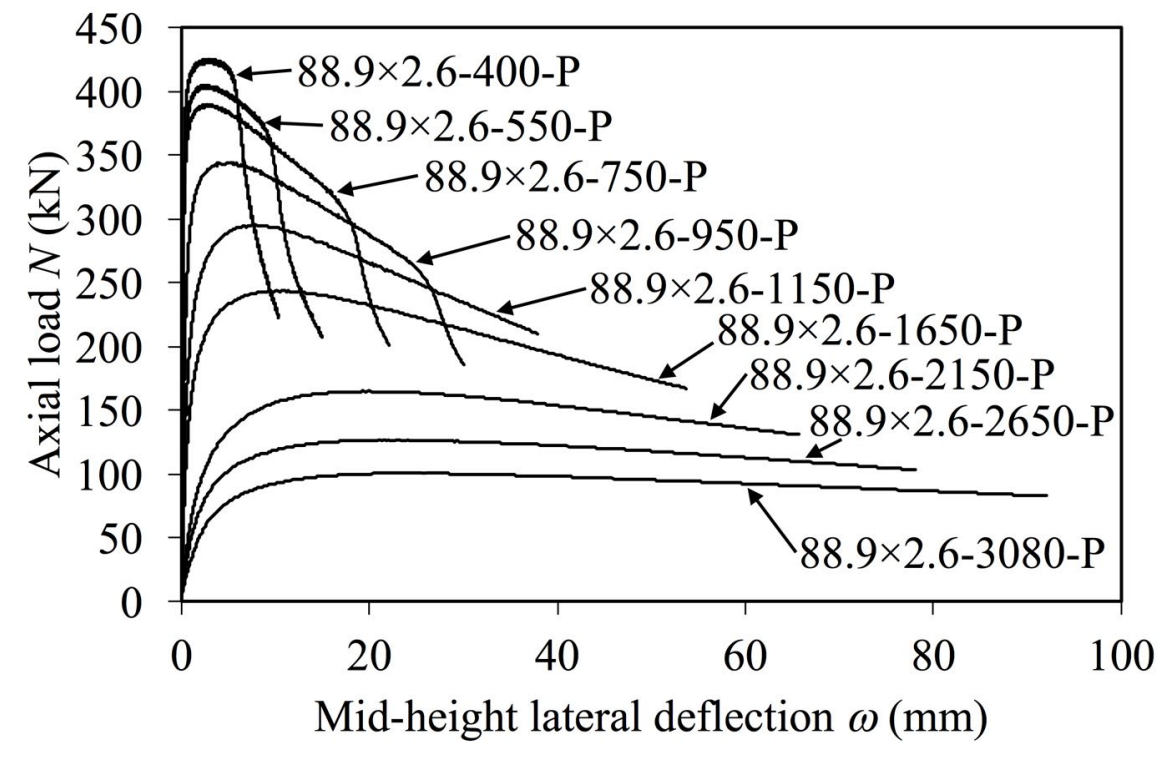

Figure 10: Experimental load versus mid-height lateral deflection curves for the $88.9 \times 2.6$ CHS specimens

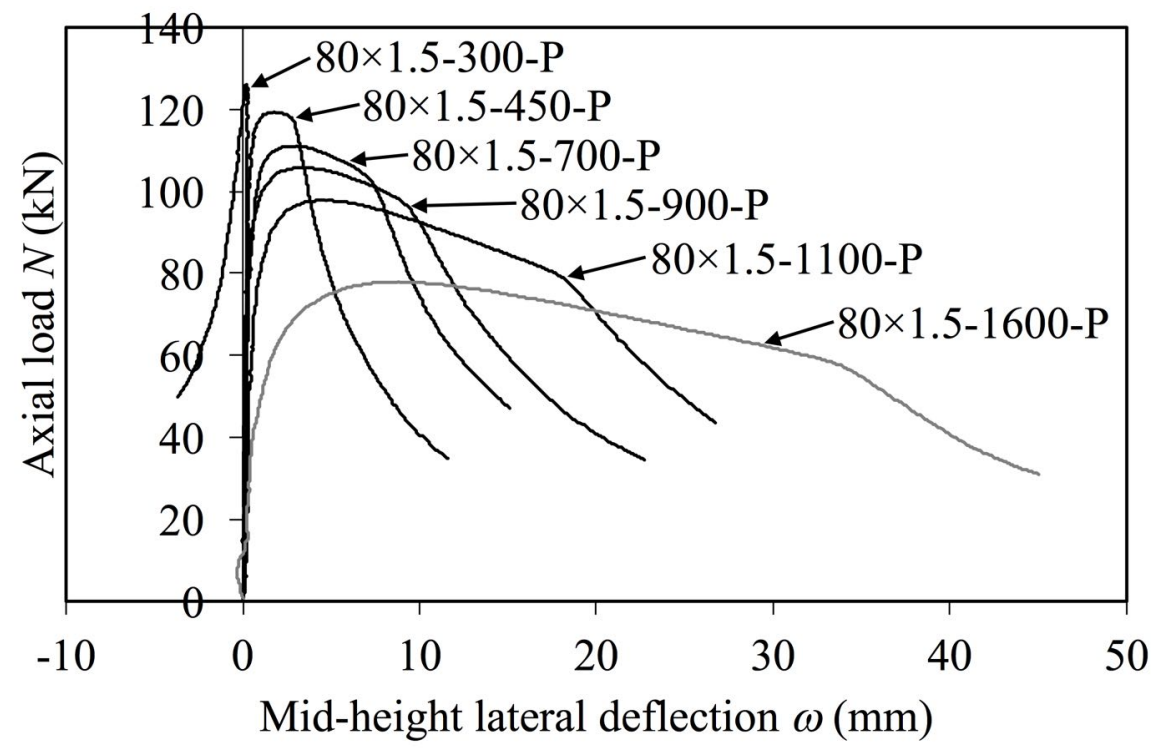

Figure 11: Experimental load versus mid-height lateral deflection curves for the $80 \times 1.5$ CHS specimens 


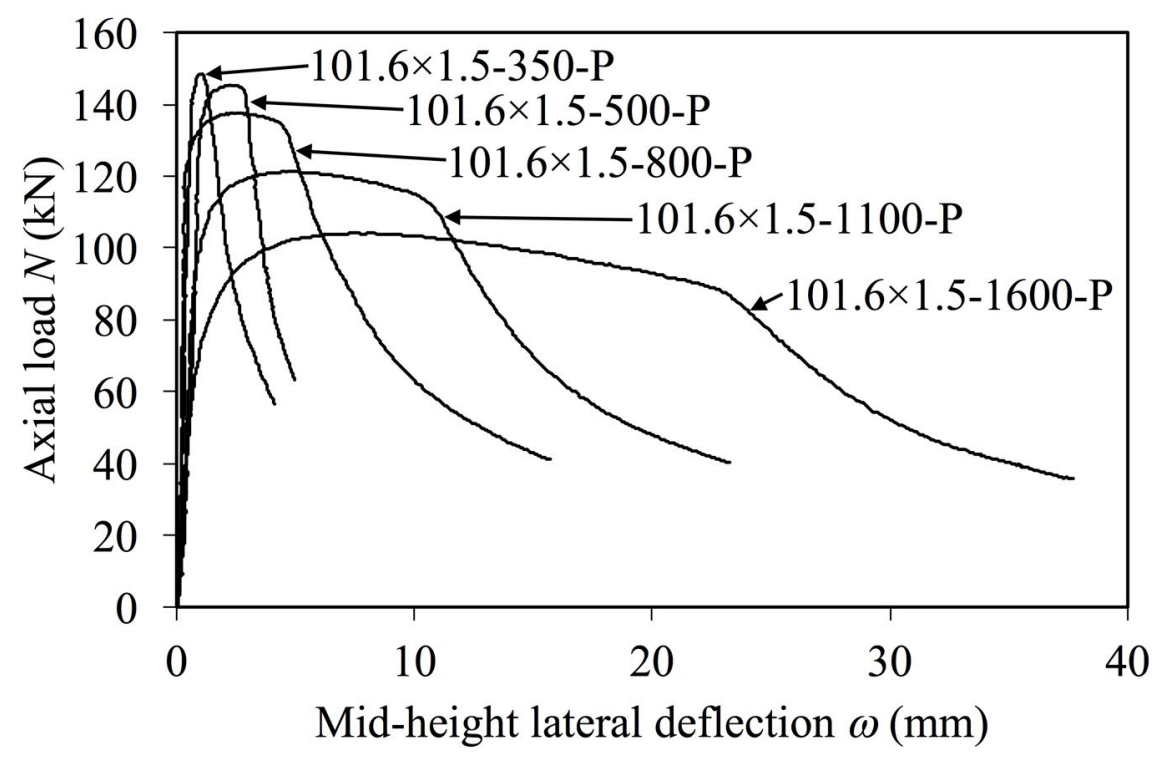

Figure 12: Experimental load versus mid-height lateral deflection curves for the $101.6 \times 1.5$ CHS specimens

The most common failure mode was global buckling, though the shorter specimens (specimens shorter than and including $106 \times 3-950-\mathrm{P}, 104 \times 2-1650-\mathrm{P}$ and $88.9 \times 2.6-950-\mathrm{P})$ also developed a mid-height local buckle on the compressed face after the peak load. The ferritic CHS specimens also exhibited global buckling failure modes, with a local buckle forming after the peak load. The very short ferritic pin-ended specimens $(80 \times 1.5-300-\mathrm{P}, 101.6 \times 1.5-350-\mathrm{P}$ and $101.6 \times 1.5-500-\mathrm{P}$ ) did not show an obvious global buckle at the peak load and instead developed 'elephant's foot' buckles close to one end of the specimen, an example of which is shown in Figure 6. Strain visualization dots were painted onto the ferritic specimens due to the highly reflective nature of the surface, and post-test reviewing of the footage filmed showed Poisson effects on the very short columns, with the painted dots moving radially outwards as the specimen was initially compressed. This radial expansion and elephant's foot failure mode has been previously observed in finite element modelling of stainless steel elliptical hollow sections (EHS) [25]. The specimens generally deflected laterally and failed in the direction induced by the applied eccentricity. However, four of the shorter specimens $(106 \times 3-$ $550-\mathrm{P}, 104 \times 2-550-\mathrm{P}, 104 \times 2-750-\mathrm{P}$ and $80 \times 1.5-300-\mathrm{P})$ changed mid-height lateral deflection direction after initially deflecting in the direction of the applied eccentricity; the applied loading eccentricities were very small in these cases and were difficult to measure accurately. The observed behaviour is therefore attributed to other small effects that encouraged a reversal of deflection direction, such as slight asymmetric geometry, local imperfections or Poisson effects. 


\section{Numerical modelling}

\subsection{General overview}

The finite element (FE) analysis package Abaqus/CAE 2016 [41] has been used to produce additional structural performance data, by means of geometrically and materially nonlinear analyses with imperfections (GMNIA). Numerical simulations of the experiments undertaken in Section 2 were first produced, with a validation study undertaken to determine the most appropriate material stress-strain relationship and imperfection amplitudes. The aim was to reproduce the full load-deformation relationships, ultimate loads and failures modes observed in the experimental study. A parametric study was then undertaken, in which the type of stainless steel, cross-section slenderness and global slenderness were varied to produce further structural data.

\subsection{Modelling assumptions}

The average measured outer diameter and wall thickness of the respective specimens were adopted in the finite element (FE) models. The four-noded doubly curved S4R shell element with reduced integration, finite membrane strains and six degrees of freedom per node is typically used for research into the structural behaviour of metallic hollow sections [17, 42, 44] and this element was utilised in the present study. The mesh size influences the accuracy of the numerical results and the computation time; a mesh size that provides converged results, particularly for failure loads and the corresponding deformations, but that is still computationally efficient, is desired. A mesh size with longitudinal and circumferential dimensions of the wall thickness $t$ was chosen, following a sensitivity study reported by Buchanan [45]; this mesh size was also adopted in previous CHS modelling by others [16, 17, 46].

Both tensile and compressive properties have been considered in the models to assess the influence of the non-symmetrical stress-strain response of stainless steel [3], as seen in the experimental results shown in Table 4. Tensile and compressive stress-strain relationships were produced by determining the compound Ramberg-Osgood material properties from the tensile coupons and compressive stub column responses measured in Section 2 [30-32]. The stub column stress-strain relationships include the effects of local buckling and therefore the compressive stress-strain curve was extrapolated, beyond the onset of local buckling, in parallel with the tensile stress-strain curve up to the ultimate tensile material stress $\sigma_{\mathrm{u}}$. Abaqus/CAE 2016 [41] requires the material properties to be inputted as true stress and plastic strain for the chosen element type, not the engineering stress and strain measured from tensile coupon and stub column tests. The true stress $\sigma_{\text {true }}$ was calculated using Equation 5 ,

$$
\sigma_{\text {true }}=\sigma_{\text {nom }}\left(1+\varepsilon_{\text {nom }}\right)
$$


where $\sigma_{\text {nom }}$ is the nominal engineering stress and $\varepsilon_{\text {nom }}$ is the nominal engineering strain, and the true plastic strain $\varepsilon_{\text {plastic }}$ was determined from Equation 6 ,

$$
\varepsilon_{\text {plastic }}=\ln \left(1+\varepsilon_{\text {nom }}\right)-\frac{\sigma_{\text {true }}}{E}
$$

where $E$ is the Young's modulus. Note that for the compressive material properties, nominal engineering strains $\varepsilon_{\text {nom }}$ were input as negative values in Equations 5 and 6 .

Membrane residual stresses have been observed to be small in cold-formed tubular sections and can therefore be neglected [7, 47]. The through thickness residual stresses are larger and should therefore be considered but, as discussed by Rasmussen and Hancock [7] and Jandera et al. [48], these residual stresses are already implicitly incorporated into the models by utilising the measured material properties.

The ends of the FE models of the pin-ended members were constrained to the movement of a longitudinally offset reference point, positioned at the rotation point of the knife edges, with the bottom end only allowing the knife edge rotation and the top end allowing both rotation and longitudinal shortening. These boundary conditions allow the ends of the cylinder to rotate about the knife edges, whilst remaining flat and undistorted. Rotation at both ends was restrained for the stub column FE models. The load was applied through the top reference point. For some of the more locally slender FE models, cross-section symmetry was used to halve the model size, due to the computing limitations of a desktop computer. A symmetrical boundary condition was applied along the longitudinal line of symmetry that prevents physical translation across it and rotation perpendicular to its plane.

Local and global geometric imperfections were incorporated into the finite element models and took the form of the lowest local and global buckling mode shapes obtained from a prior elastic buckling analysis. The global imperfection is used to simulate both the initial global imperfection of the specimen and any additional applied eccentricity required to attain a combined equivalent global imperfection and applied eccentricity of $L / 1000$. Two global imperfection amplitudes, the measured value $\left(\omega_{0}+e_{0}\right)$ and a fraction of the effective length $L / 1000$, and two local imperfection amplitudes, $t / 10$ and $t / 100$, where $t$ is the section thickness, were considered. It was not always possible to achieve a global buckling mode for the very short columns; if a global buckling mode was not attainable (in the first 200 modes) only a local buckling mode was used for the local imperfection. The modified Riks method was used to follow the nonlinear post-ultimate response of the models.

\subsection{Validation}

Finite element models of the tested specimens in Section 2 were produced and validated initially by comparing the normalised average predicted ultimate load $N_{\mathrm{u}, \mathrm{FE}} / N_{\mathrm{u} \text {,exp }}$ and the mid-height lateral deformation at the ultimate load $\omega_{\mathrm{u}, \mathrm{FE}} / \omega_{\mathrm{u} \text {,exp }}$ with the measured value, as shown in Tables 10 and 11 respectively. The ultimate load was generally well reproduced 
Table 10: Summary of the average $N_{\mathrm{u}, \mathrm{FE}} / N_{\mathrm{u}, \exp }$ values for varying material properties and imperfection amplitudes

\begin{tabular}{|c|c|c|c|c|c|}
\hline Material model & \multicolumn{2}{|c|}{ Tensile properties } & \multicolumn{2}{|c|}{ Stub properties } & \\
\hline Local imperfection amplitude & $t / 10$ & $t / 10$ & $t / 10$ & $t / 10$ & $t / 100$ \\
\hline Global imperfection amplitude & $\mathrm{L} / 1000$ & $\omega_{0}+e_{0}$ & $\mathrm{~L} / 1000$ & $\omega_{0}+e_{0}$ & $\omega_{0}+e_{0}$ \\
\hline Mean $N_{\mathrm{u}, \mathrm{FE}} / N_{\mathrm{u}, \exp }$ & 1.025 & 1.024 & 1.012 & 1.011 & 1.013 \\
\hline $\mathrm{COV} N_{\mathrm{u}, \mathrm{FE}} / N_{\mathrm{u}, \exp }$ & 0.082 & 0.081 & 0.046 & 0.046 & 0.046 \\
\hline
\end{tabular}

Table 11: Summary of the average $\omega_{\mathrm{u}, \mathrm{FE}} / \omega_{\mathrm{u}, \exp }$ values for varying material properties and imperfection amplitudes

\begin{tabular}{|c|c|c|c|c|c|}
\hline Material model & \multicolumn{2}{|c|}{ Tensile properties } & \multicolumn{2}{|c|}{ Stub properties } & \\
\hline Local imperfection amplitude & $t / 10$ & $t / 10$ & $t / 10$ & $t / 10$ & $t / 100$ \\
\hline Global imperfection amplitude & $\mathrm{L} / 1000$ & $\omega_{0}+e_{0}$ & $\mathrm{~L} / 1000$ & $\omega_{0}+e_{0}$ & $\omega_{0}+e_{0}$ \\
\hline Mean $\omega_{\mathrm{u}, \mathrm{FE}} / \omega_{\mathrm{u}, \exp }$ & 0.617 & 0.612 & 0.720 & 0.711 & 0.708 \\
\hline $\operatorname{COV} \omega_{\mathrm{u}, \mathrm{FE}} / \omega_{\mathrm{u}, \exp }$ & 0.920 & 0.923 & 0.818 & 0.821 & 0.834 \\
\hline
\end{tabular}

by the finite element models, with the models using the stub column material properties on average more accurate and less scattered than those using the tensile coupon material properties. The models are observed to be on average fairly insensitive to the local and global imperfection amplitudes, as highlighted by the models based on stub column properties having similar averages and identical coefficient of variation (COV) values (in Table 10); the most accurate predictions on average for the ultimate load were obtained with a local imperfection amplitude of $t / 10$ and using the measured global imperfection amplitude $\left(\omega_{0}+e_{0}\right)$. The mid-height lateral deformation at the ultimate load is less consistently replicated by the finite element models than the ultimate load; this is attributed primarily to the greater inherent variability of deformations at peak loads in problems of the studied kind, as further discussed in the following paragraph. Again the models are more accurate and consistent in their deformation predictions using the stub column material properties than the tensile coupon material properties. It can also be observed that on average the deformations are more sensitive to the imperfection amplitude than the ultimate load. The most accurate and least scattered deformation predictions are obtained using the stub column properties with a local imperfection amplitude of $t / 10$ and a global imperfection amplitude of $L / 1000$, though the results are very similar when the measured global imperfection amplitudes are adopted.

The load-deformation relationships and failure modes can also be compared between the physical experiments and the numerical models. The measured experimental and finite element analysis load mid-height lateral deformation curves for the $88.9 \times 2.6-950-\mathrm{P}$ and $106 \times 3-1650-\mathrm{P}$ specimens are plotted in Figures 13 and 14 respectively, which show that the load-deformation history can be accurately replicated. These figures also show how the flat nature of the load-deformation curve can result in a large difference between the deformation at the peak load for the experiment and numerical modelling, even with the overall curve being relatively well reproduced. The experimental and FE model failure modes 


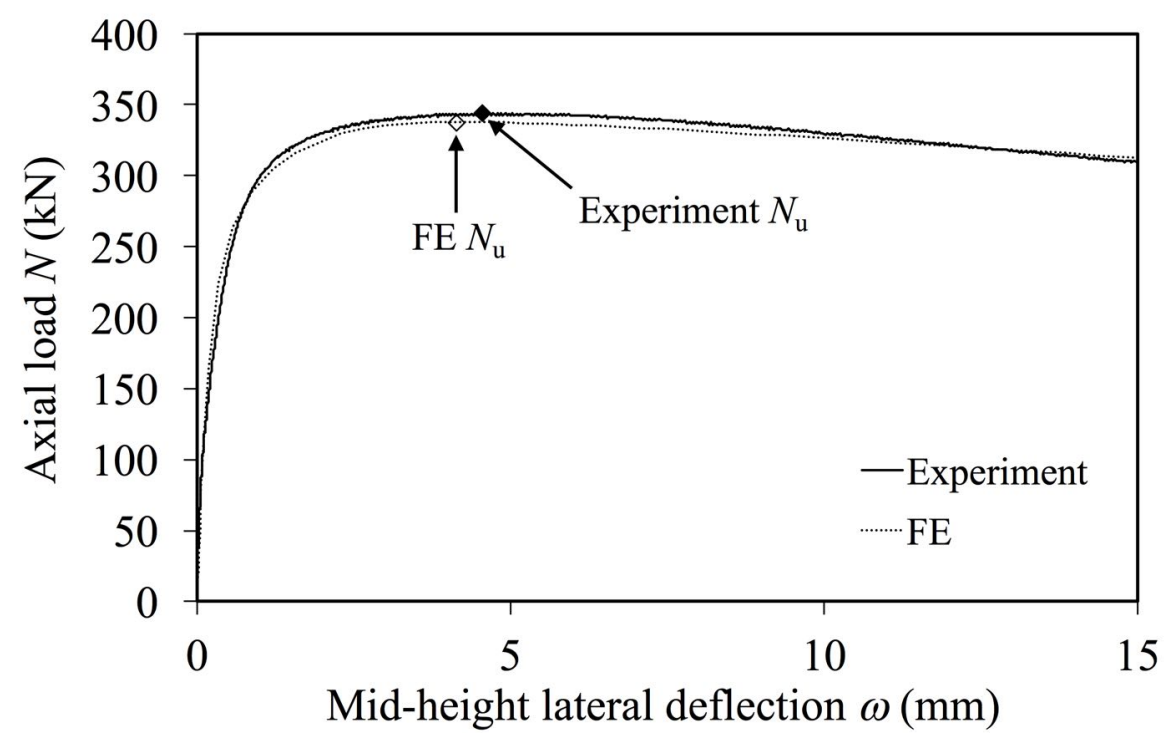

Figure 13: Experimental and FE load versus mid-height lateral deflection curves for the 88.9 $\times 2.6-950-\mathrm{P}$ specimen

of the $104 \times 2-750-\mathrm{P}$ and $106 \times 3-3080-\mathrm{P}$ specimens are shown in Figures 15 and 16, where close correlation may be observed.

Overall the most accurate predictions for ultimate load and mid-height deformation are attained when using the stub column material properties with a local imperfection amplitude of $t / 10$ and a global imperfection amplitude of the measured values or $L / 1000$; it has also been shown that the load-deformation histories and failure modes are well replicated numerically.

\subsection{Parametric study}

In this sub-section, the validated FE models are employed for a parametric investigation. A Python script was developed to allow a large number of finite element models to be produced and run efficiently. A $50 \mathrm{~mm}$ offset was applied between the cylinder end and the knife edge rotation point to simulate the same end plate and knife edge arrangement as in the UPC ferritic stainless steel column tests. The models used the stub column material properties, along with a $t / 10$ local imperfection amplitude and a $L / 1000$ global imperfection amplitude. Following the linear buckling analysis, each model was inspected to determine the most appropriate (e.g. avoiding modes in which the deformation was highly localised towards the member ends) local and global buckling modes and these were then used in the nonlinear analyses. The nonlinear analyses were monitored and terminated once the peak load had been reached to reduce unnecessary computation.

Six cross-sections were modelled for each of the three common types of stainless steel used in construction. The austenitic cross-sections were based on the measured material properties 


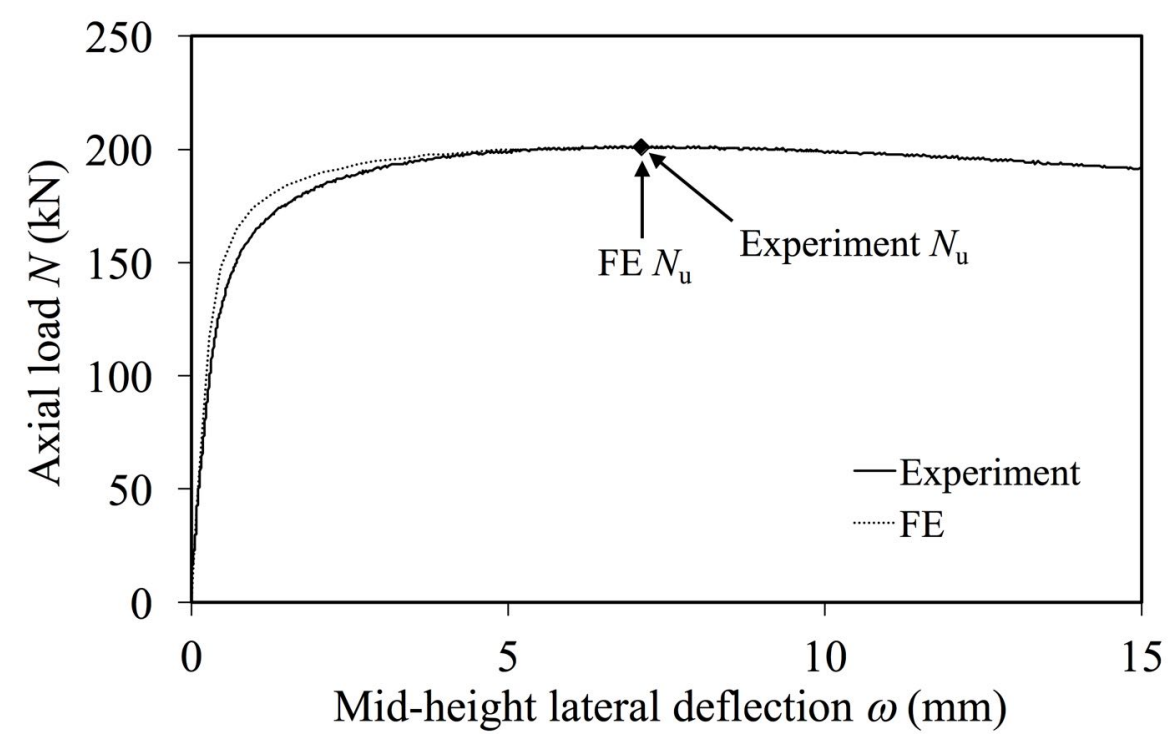

Figure 14: Experimental and FE load versus mid-height lateral deflection curves for the $106 \times 3-1650-\mathrm{P}$ specimen
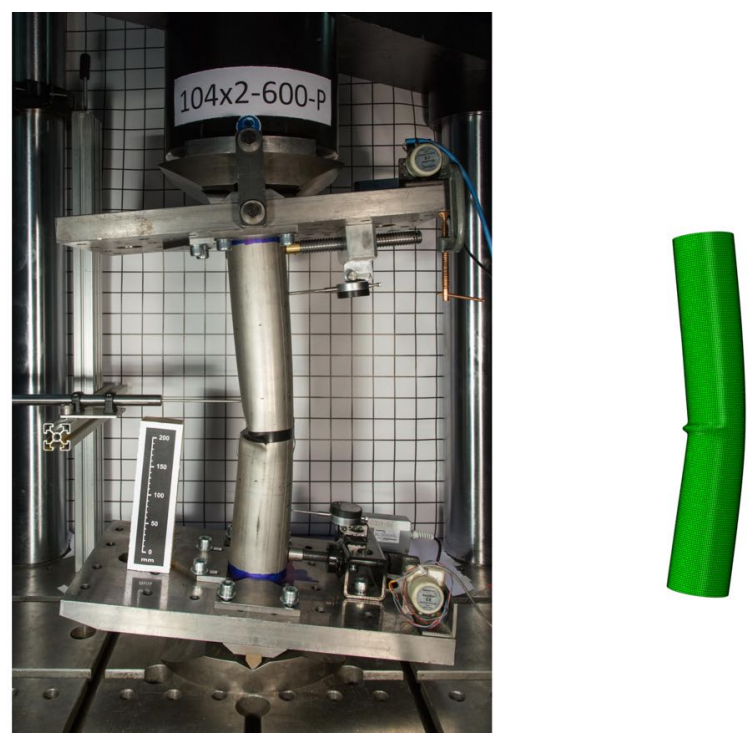

Figure 15: Experimental and FE failure modes for the $104 \times 2-750-\mathrm{P}$ specimen 

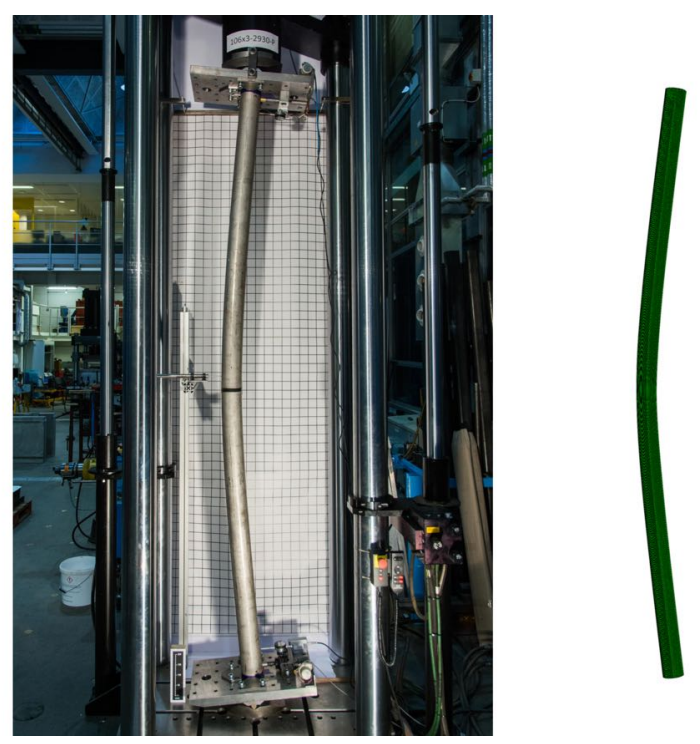

Figure 16: Experimental and FE failure modes for the $106 \times 3-3080-\mathrm{P}$ specimen

from the $106 \times 3 \mathrm{CHS}$, the duplex cross-sections from the $88.9 \times 2.6$ CHS and the ferritic cross-sections from the $101.6 \times 1.5 \mathrm{CHS}$. The local slendernesses were varied over a wide range of values covering the four EN 1993-1-4 (2015) cross-section classes, with the member lengths chosen to provide a range of global slenderness values up to approximately $\bar{\lambda}=2.5$. The modelled cross-sections are summarised in Table 12, where $D / t \varepsilon^{2}$ is the EN 1993-1-4 (2015) local slenderness parameter and $\varepsilon=\left(235 / \sigma_{0.2} E / 210000\right)^{0.5}$; in compression, $D / t \varepsilon^{2} \leq 50$ corresponds to a class $1 \mathrm{CHS}, D / t \varepsilon^{2} \leq 70$ denotes a class $2 \mathrm{CHS}$ and $D / t \varepsilon^{2} \leq 90$ refers to a class 3 CHS, otherwise the CHS is class 4 . The other parameters summarised in Table 12 are the minimum and maximum global slendernesses of the modelled cylinders, $\bar{\lambda}_{\text {min }}$ and $\bar{\lambda}_{\text {max }}$, and the number of FE models per cross-section. The specimens where only half the cross-section was modelled and symmetry boundary conditions were employed are also noted in Table 12.

\section{Existing design methods}

EN 1993-1-4 (2015) provides design rules for the flexural buckling resistance of stainless steel CHS columns. Other researchers have proposed improvements to these rules using both direct and iterative methods. Rasmussen and Rondal [21], Young and Ellobody [22], Ellobody and Young [23] and Theofanous et al. [25] have all proposed changes to the existing buckling curve and their proposals are evaluated in the context of the collated existing experimental results and the new results produced in this study. The measured geometric and compressive (where available, or else tensile) material properties are used in the comparisons and all safety factors are taken to be equal to unity. The iterative methods proposed by Rasmussen and Hancock [7], Hradil et al. [49] and Shu et al. [26] have not been evaluated in this study. 


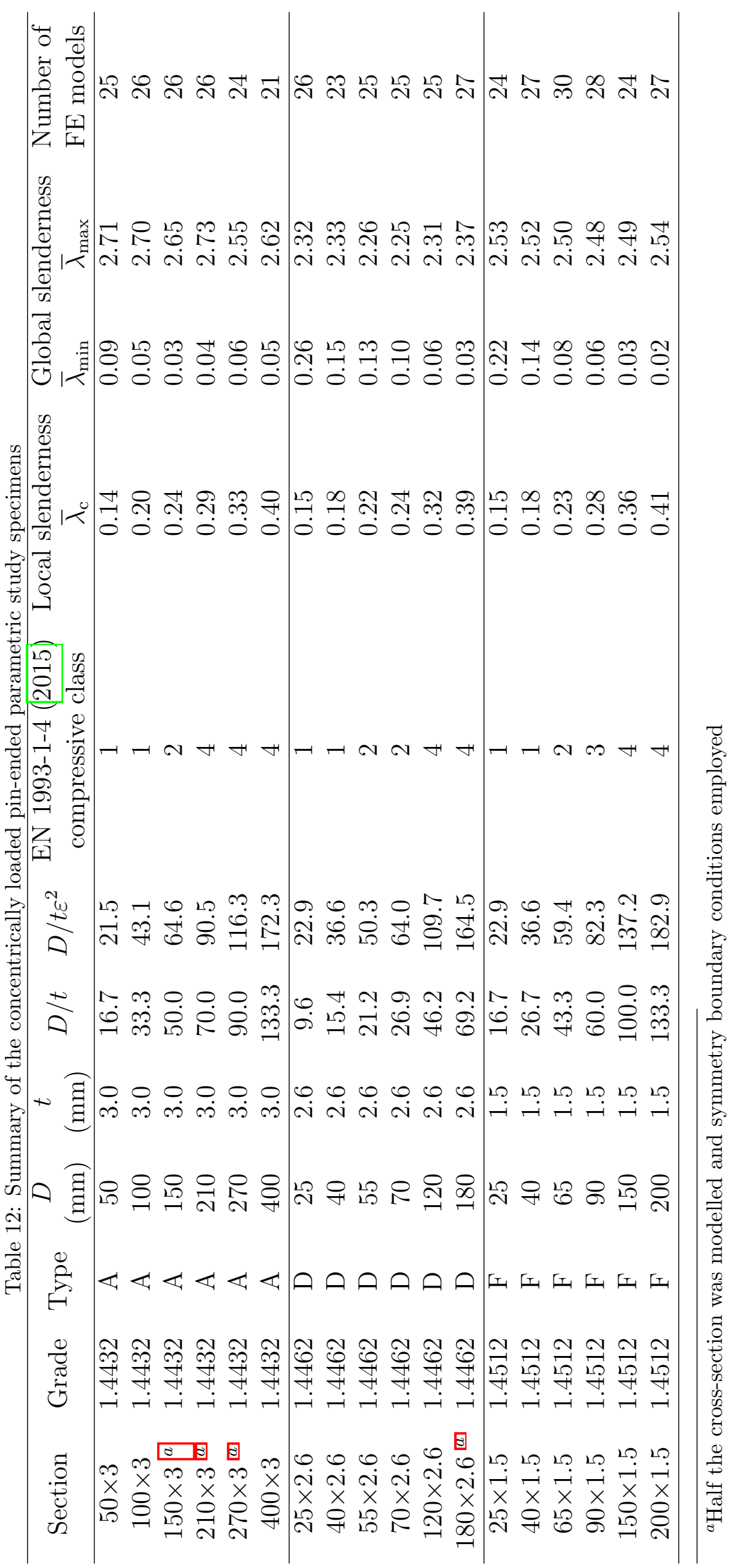




\subsection{EN 1993-1-4 (2015) design provisions}

EN 1993-1-4 (2015) provides a single flexural buckling curve for both hot-finished and coldformed stainless steel hollow sections. The flexural buckling resistance $N_{\mathrm{b}, \mathrm{Rd}}$ of members can be determined from Equation 7 .

$$
N_{\mathrm{b}, \mathrm{Rd}}=\frac{\chi A \sigma_{0.2}}{\gamma_{\mathrm{M} 1}} \text { for class } 1,2 \text { and } 3 \text { cross-sections, }
$$

and from Equation 8 ,

$$
N_{\mathrm{b}, \mathrm{Rd}}=\frac{\chi A_{\mathrm{eff}} \sigma_{0.2}}{\gamma_{\mathrm{M} 1}} \text { for class } 4 \text { cross-sections, }
$$

where $\chi$ is the non-dimensional buckling reduction factor and $\gamma_{\mathrm{M} 1}$ is the partial safety factor. The reduction factor $\chi$ is based upon the Perry curve [50] and can be determined from Equation 9 .

$$
\chi=\frac{1}{\phi+\sqrt{\phi^{2}-\bar{\lambda}^{2}}}
$$

where $\phi$ is the operational parameter from Equation 10 .

$$
\phi=\frac{1}{2}\left(1+\eta+\bar{\lambda}^{2}\right)
$$

The imperfection parameter $\eta$ can be determined from Equation 11 ,

$$
\eta=\alpha\left(\bar{\lambda}-\bar{\lambda}_{0}\right)
$$

where for stainless steel hollow cross-sections the imperfection factor $\alpha=0.49$ and limiting slenderness $\bar{\lambda}_{0}=0.4$ (defining the length of the $\chi=1$ plateau); these two parameters control the shape of the buckling curve and can be adjusted to reflect the influence of different degrees of material nonlinearity, initial geometric imperfections and residual stresses.

The reduction factor $\chi$ from EN 1993-1-4 (2015) is plotted with all of the existing and new experimental and numerical cold-formed stainless steel CHS column buckling data in Figure 17, the existing and new experimental test data in Figure 18 and with the full austenitic, duplex and ferritic column datasets in Figures 19, 20 and 21 respectively. Apart for the $101.6 \times 1.5 \mathrm{CHS}$, the class $4 \mathrm{CHS}$ tested herein are all close to the class 3 limit. The vertical axes in Figure 17,21 are therefore the ultimate axial load normalised by the yield load $N_{\mathrm{u}} /\left(A \sigma_{0.2}\right)$ or effective area times the proof stress $N_{\mathrm{u}} /\left(A_{\text {eff }} \sigma_{0.2}\right)$. The numerical results for the class 4 CHS are not plotted as these are generally further away from the class 3 limit, as seen in Table 12, and the resistance predictions are particularly conservative due to the use of the effective area expression, previously reproduced as Equation 3. Excluding these class 4 data enables an assessment of global buckling only. It is readily apparent from these Figures that the current EN 1993-1-4 (2015) design curve for stainless steel CHS columns is unsuitable for low and intermediate global slenderness values with unconservative predictions of the 


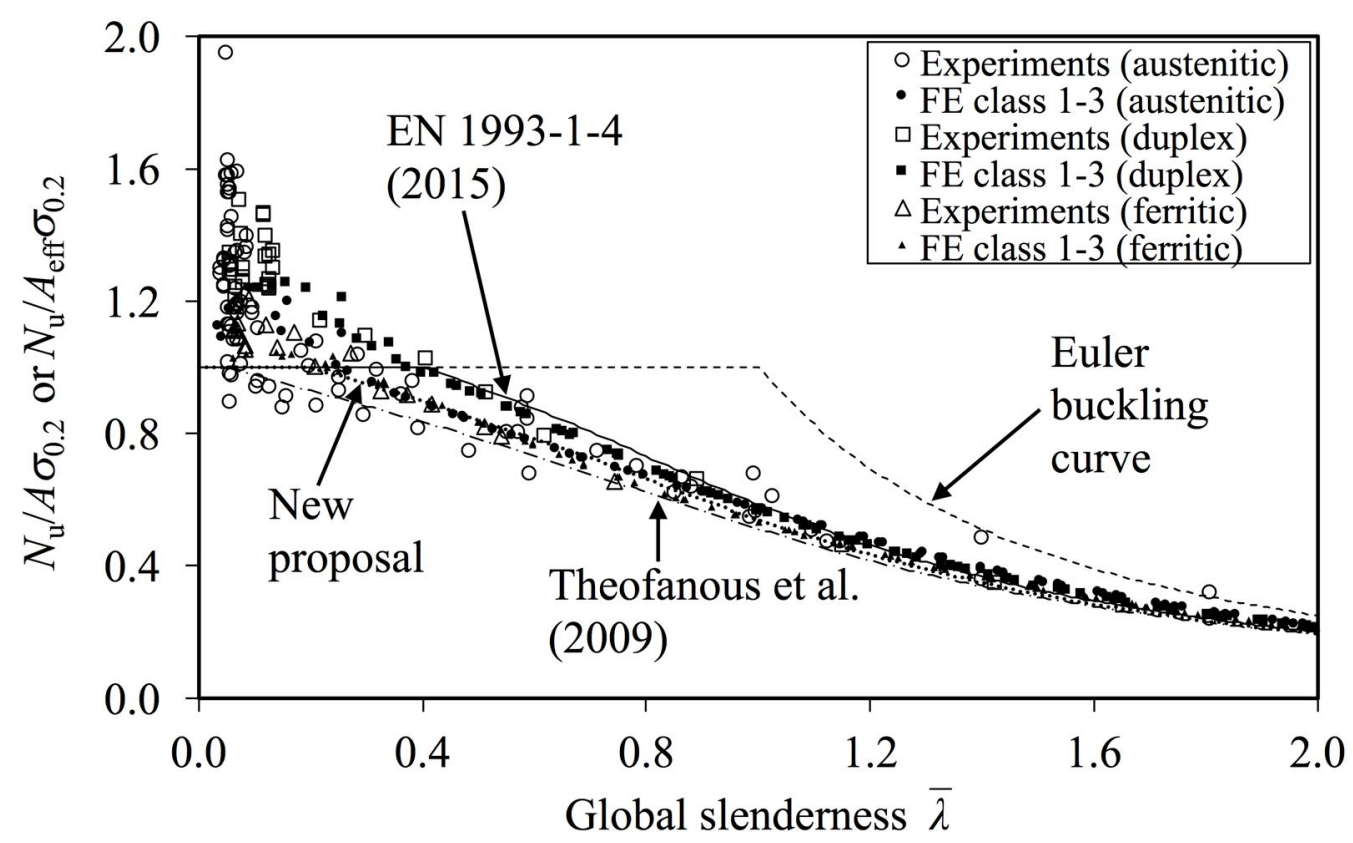

Figure 17: Comparison of all experimental and finite element results with buckling curves

ultimate flexural buckling resistance. There are a number of very unconservative resistance predictions for the fixed ended columns tested by Young and Hartono [11], which form part of the existing austenitic dataset in Figures 17, 19, the normalised ultimate capacity of these columns is substantially lower than those obtained from other existing tests and the column tests undertaken in this study. Conversely, there are some conservative resistance predictions for existing column tests undertaken by Rasmussen and Hancock [7], with a normalised capacity noticeably higher than other new and existing tests. In the very low slenderness range the data points for the stockier cross-sections are well in excess of the yield load due to strain hardening, which is not currently considered in EN 1993-1-4 (2015) [51]; this was addressed in Buchanan et al. 38] through the extension of the continuous strength method (CSM) to CHS.

\subsection{Rasmussen and Rondal [21] design provisions}

Rasmussen and Rondal [21] focused on producing flexural buckling curves for nonlinear materials and proposed a new nonlinear imperfection factor expression which is reproduced as Equation 12 .

$$
\eta=\alpha\left(\left(\bar{\lambda}-\lambda_{1}\right)^{\beta}-\lambda_{0}\right)
$$

The parameters $\alpha, \beta, \lambda_{0}$ and $\lambda_{1}$ can be determined from the compressive Ramberg-Osgood 


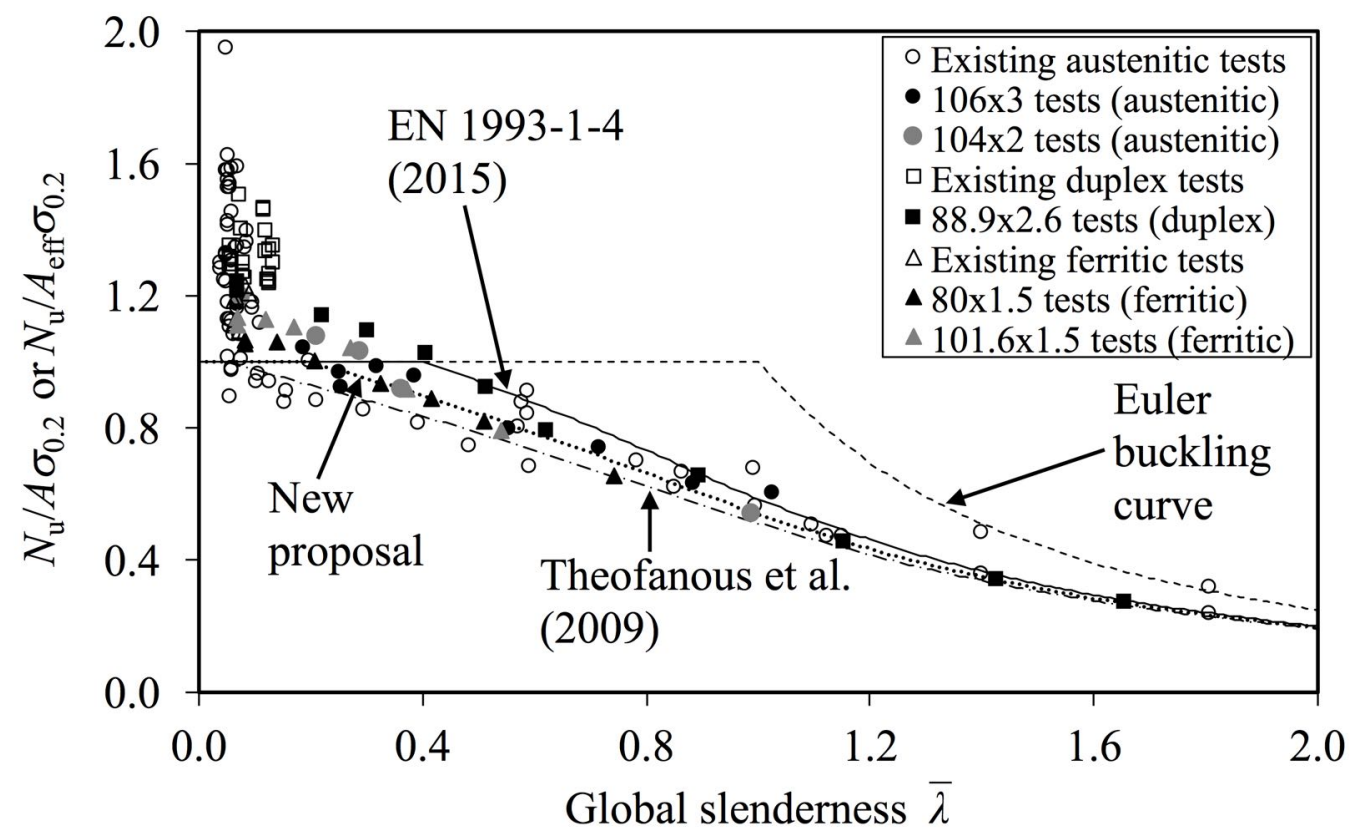

Figure 18: Comparison of all experimental results with buckling curves

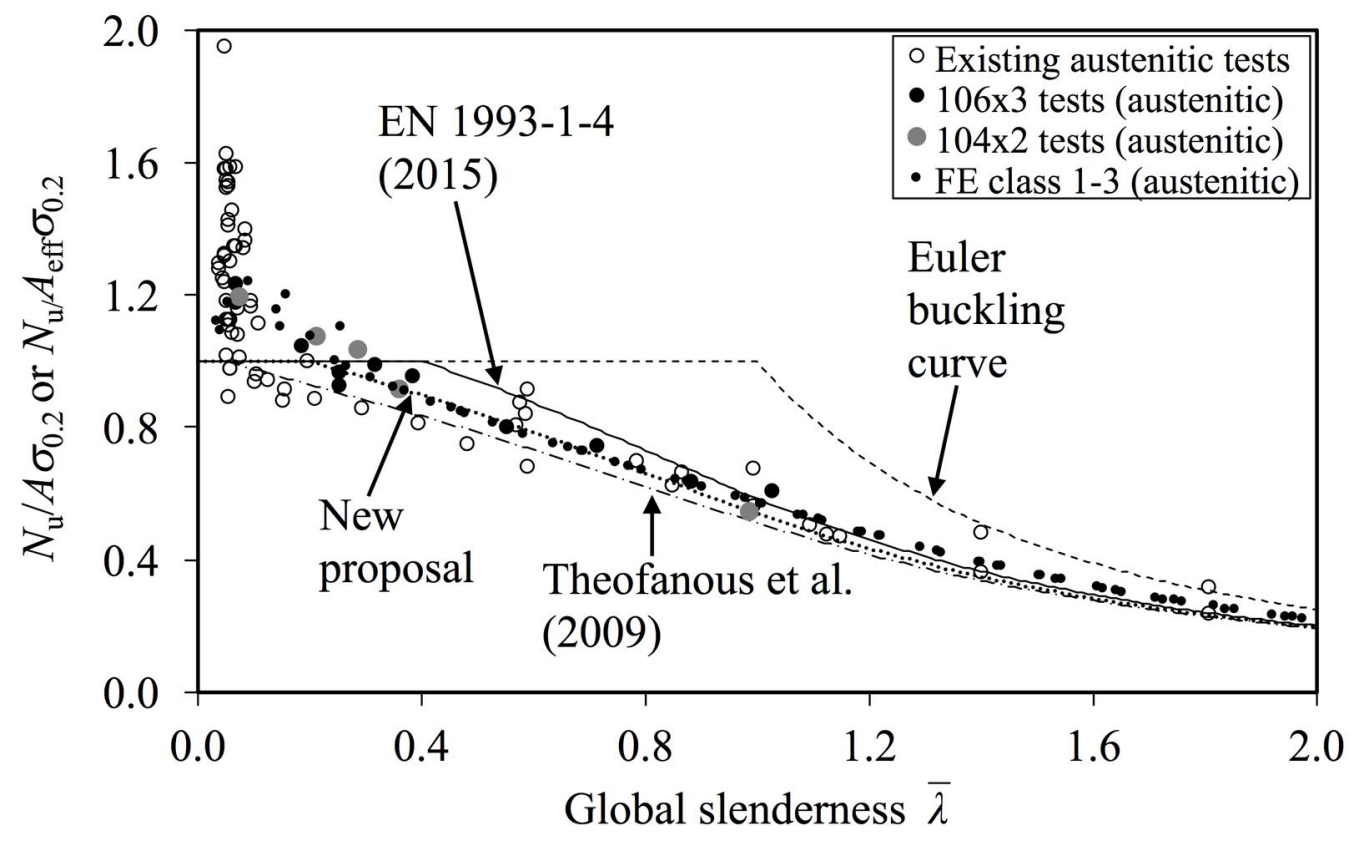

Figure 19: Comparison of austenitic experimental and finite element results with buckling curves 


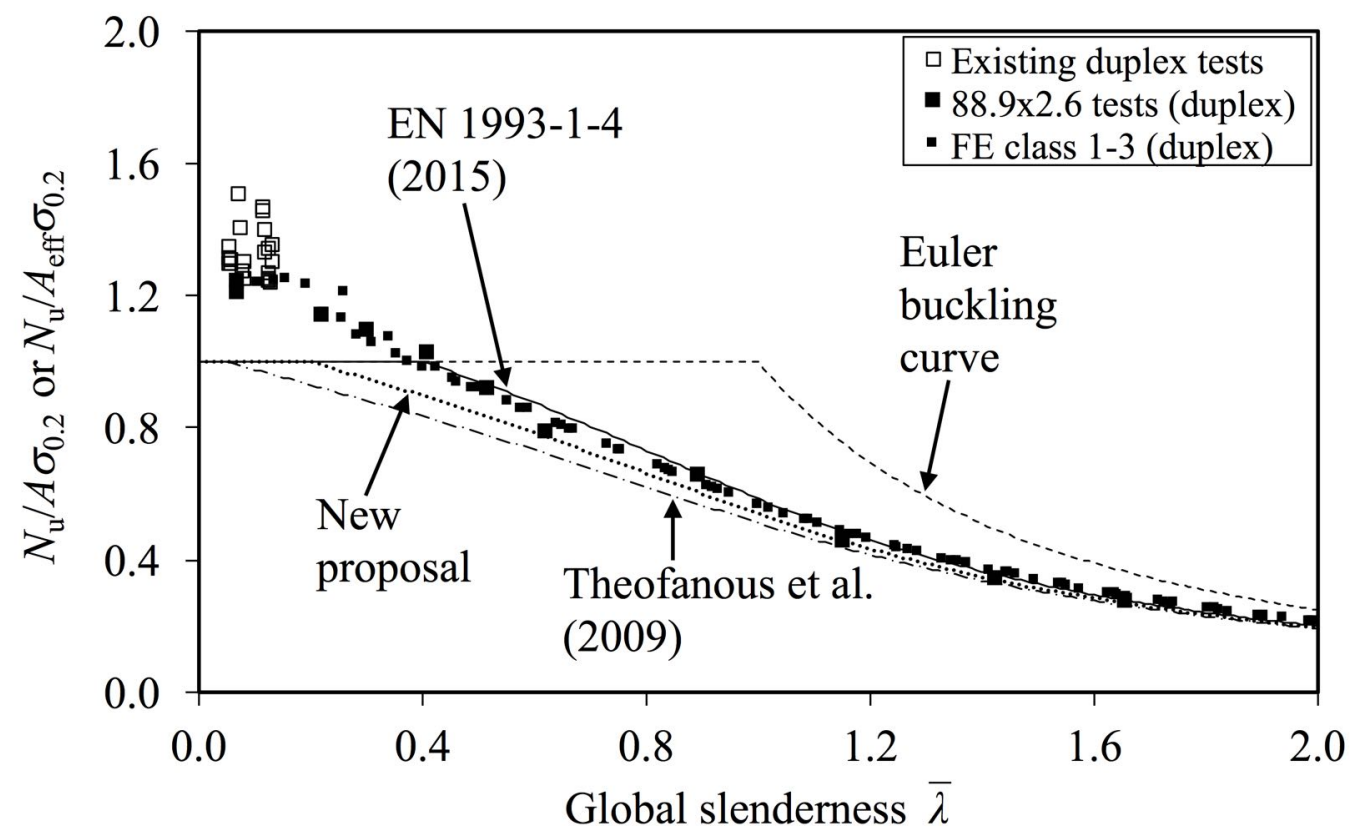

Figure 20: Comparison of duplex experimental and finite element results with buckling curves

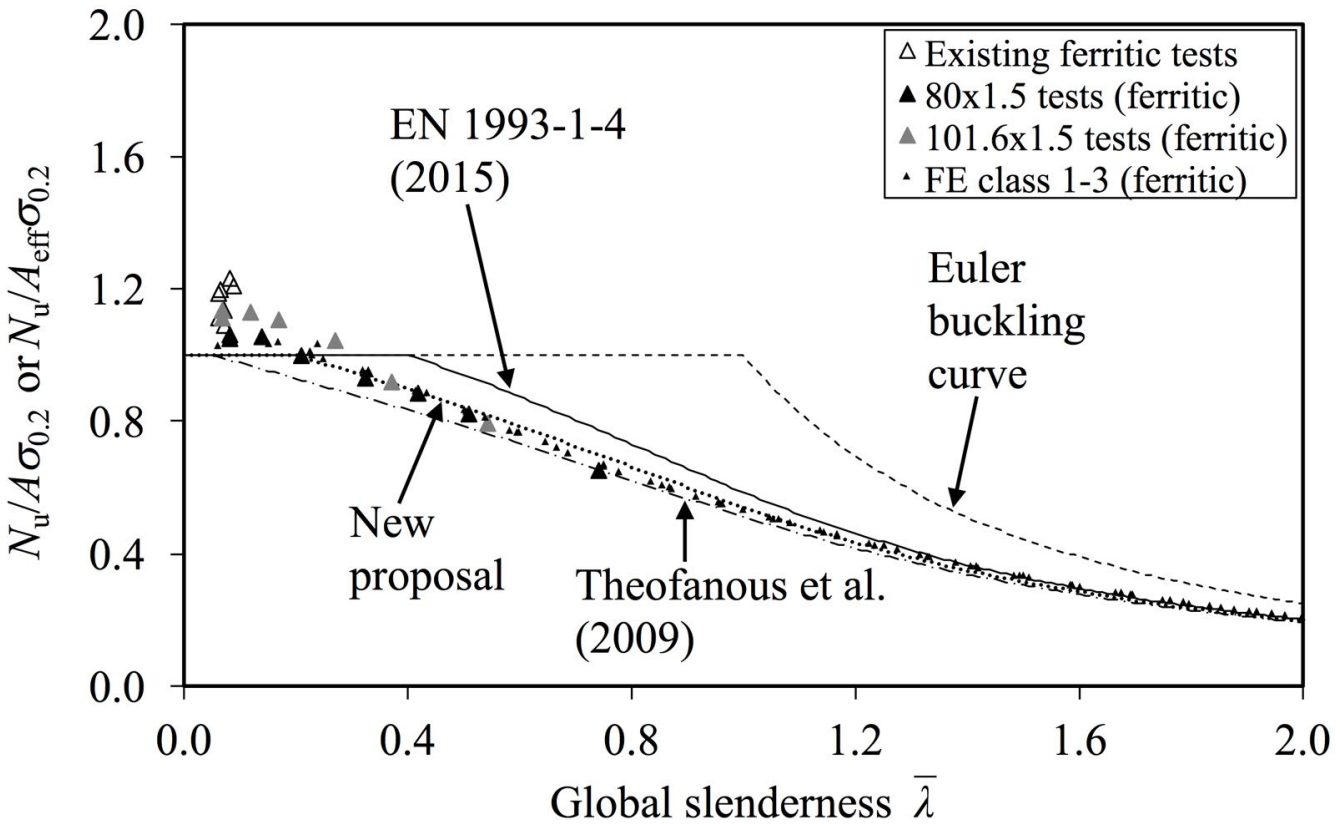

Figure 21: Comparison of ferritic experimental and finite element results with buckling curves 
material properties using Equations 13 to 16 [51,

$$
\begin{gathered}
\alpha=\frac{1.5}{\left(e^{0.6}+0.03\right)\left(n^{\left(0.0048 / e^{0.55}\right)+1.4}+13\right)}+\frac{0.002}{e^{0.6}} \\
\beta=\frac{0.36 \exp (-n)}{e^{0.45}+0.007}+\tanh \left(\frac{n}{180}+\frac{6 \times 10^{-6}}{e^{1.4}}+0.04\right) \\
\lambda_{0}=0.82\left(\frac{e}{e+0.0004}-0.01 n\right) \geq 0.2 \\
\lambda_{1}=0.8 \frac{e}{e+0.0018}\left[1-\left(\frac{n-5.5}{n+(6 e-0.0054 / e+0.0015)}\right)^{1.2}\right]
\end{gathered}
$$

where $e=\sigma_{0.2} / E$. They noted that due to the rounded nature of the material response of stainless steels the imperfection parameter $\eta$ should have a nonlinear form and be a function of $n$ and $e$ to reflect the variation of the degree of roundness of the stress-strain curve with stainless steel grades.

\subsection{Young and Ellobody [22] design provisions}

Young and Ellobody [22] and Ellobody and Young [23] undertook a parametric study on austenitic stainless steel fixed ended CHS columns with slender cross-sections and on austenitic and duplex fixed ended CHS columns with non-slender cross-sections. Two new buckling curves for CHS columns with non-slender cross-sections were proposed for normal strength (austenitic) and high strength (duplex) columns, with $\alpha=0.8$ and $\bar{\lambda}_{0}=0.2$ and $\alpha=0.4$ and $\bar{\lambda}_{0}=0.3$ in Equation 11 respectively. For slender cross-sections, the existing EN 1993-1-4 (2015) column curve with a new effective area $A_{\text {eff }}$ expression, reproduced as Equation 17 . was proposed.

$$
A_{\text {eff }}=A \varepsilon\left(\frac{125}{D / t}\right)^{0.1}
$$

Ellobody and Young [23] noted that the duplex stainless steel finite element results were reasonably well predicted by the existing EN 1993-1-4 (2015) buckling curve, which is generally also the case in this study, as seen in Figure 20. The ferritic column results are taken to be normal strength stainless steel and the existing compressive EN 1993-1-4 (2015) class limits are applied in this study.

\subsection{Theofanous et al. [25] design provisions}

Theofanous et al. [25] proposed a new buckling curve for stainless steel CHS and EHS in the format of the existing EN 1993-1-4 (2015) expressions (as given by Equations 7 to 11), with an imperfection factor $\alpha=0.49$ and limiting slenderness $\bar{\lambda}_{0}=0.05$ in Equation 11 . The proposed buckling curve was established using experimental CHS and elliptical hollow section (EHS) stainless steel column buckling results and was statistically validated using 
EN 1990 (2005). This buckling curve has been plotted along with the experimental data in Figures 17, 21. The same imperfection factor and limiting slenderness were also proposed by Ashraf et al. [24], although the $0.2 \%$ proof stress $\sigma_{0.2}$ was replaced with an effective buckling stress $\sigma_{\text {eff. }}$

\subsection{New flexural buckling curve proposal}

The enlarged experimental and numerical datasets comprehensively covering the three main families of stainless steel - austenitic, duplex and ferritic, is now used to propose a new flexural buckling curve for cold-formed stainless steel CHS columns. A safe and efficient buckling curve that did not require iteration and that achieved the target partial safety factor of $\gamma_{\mathrm{M} 1}=1.1$ in EN 1993-1-4 (2015) was sought. The chosen buckling curve is of the same format as the existing EN 1993-1-4 (2015) equations (as given by Equations 9 to 11), and has the same imperfection factor $\alpha=0.49$, but with a reduced limiting slenderness $\lambda_{0}=0.20$ in Equation 11. This reduction in the limiting slenderness $\bar{\lambda}_{0}$ from 0.40 to 0.20 halves the length of columns for which there is no reduction in strength due to flexural buckling. The new flexural buckling curve proposal is plotted in Figures 17,21 alongside the new and existing experimental and numerical data. Its suitability and accuracy is discussed in Section 5 and evaluated by means of reliability analysis in Section 6 .

\section{Discussion of the existing and new design provisions}

The highlighted existing and proposed design curves can be evaluated using the collated experimental and numerical cold-formed stainless steel CHS column buckling dataset. The assembled dataset is plotted, in various combinations based on the type of stainless steel and whether the results are experimental or numerical in Figures 17, 21. The existing EN 1993-1-4 (2015) buckling curve, the Euler buckling curve, the Theofanous et al. [25] proposal and the new proposed flexural buckling curve are also plotted. The other proposals cannot easily be compared in this format since the buckling curves vary with material properties. A comparison between the ultimate compressive capacities and the predictions from the considered design methods for the new experimental results and numerical class 1-3 dataset is provided in Figures 22, 23 and 24 for the austenitc, duplex and ferritic grades respectively. The considered proposals generally offer improved predictions of the ultimate capacity compared with EN 1993-1-4 (2015) for $\bar{\lambda} \leq 0.8$, although a number of results for the duplex and more slender columns lie below the Rasmussen and Rondal [21] predictions. The small number of outlying normalised predictions in Figure 22 are due to the high experimental ultimate capacities from the Rasmussen and Hancock [7] dataset, which can also be seen in Figure 19. The three high duplex predictions for the Young and Ellobody [22] and Ellobody and Young [23] proposals, in Figure 23, are the result of some of the $88.9 \times 2.6$ CHS cross-sections being classified as class 4 , leading to a low predicted ultimate load when applying the rather conservative $A_{\text {eff }}$ expression from Equation 17. The average ratio of ultimate-to-predicted capacity is reported in Table 13, along with coefficient of variation (COV) values, for all columns with class 1-3 cross-sections over the full range of global slendernesses $\bar{\lambda}$ and for columns with $\bar{\lambda} \leq 0.2$ and 


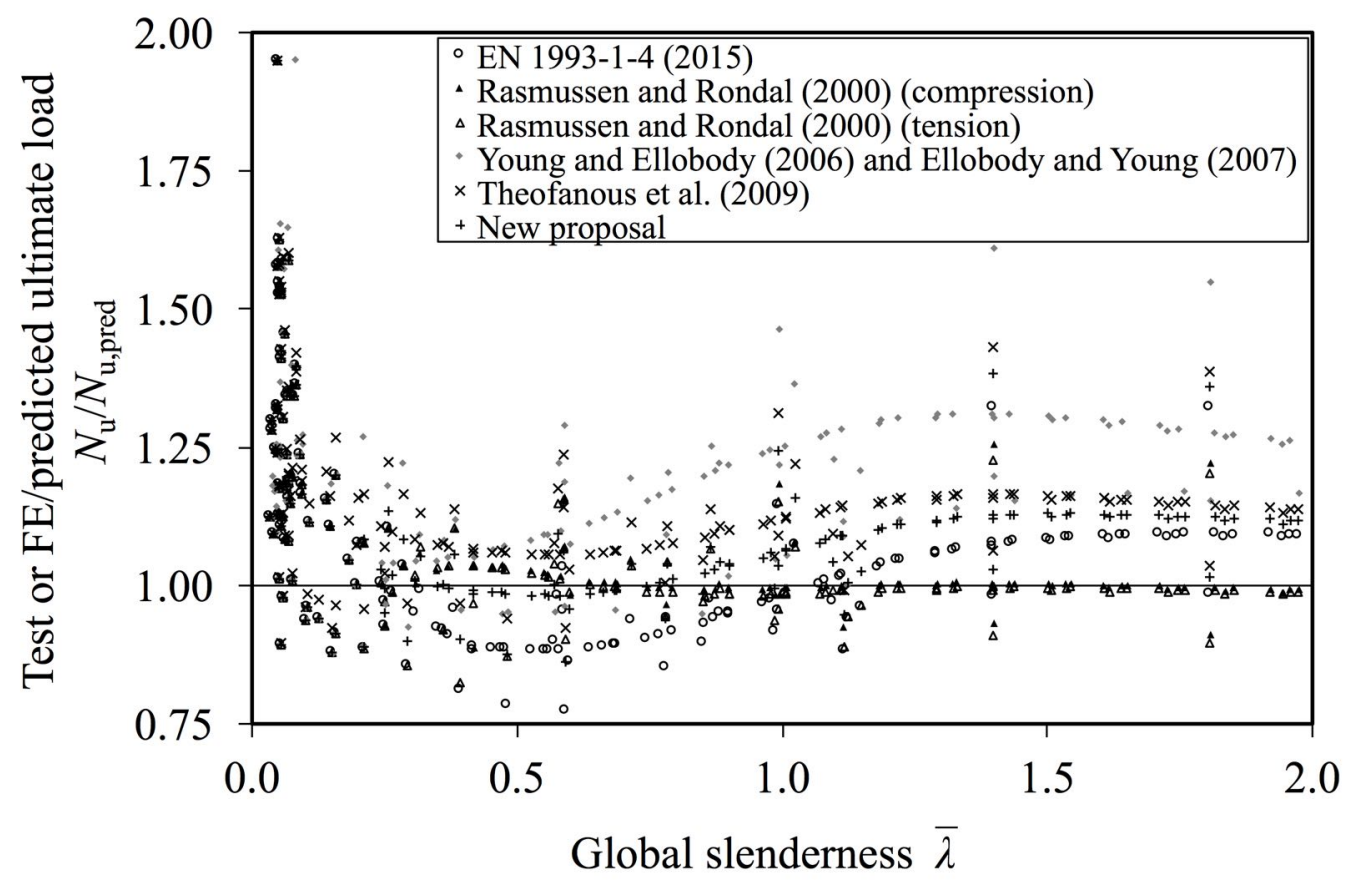

Figure 22: Comparisons of design provisions with experimental and numerical data for austenitic stainless steel CHS columns

$\bar{\lambda}>0.2$ (to differentiate between columns where member buckling effects are small and high ultimate-to-predicted ratios are achieved due to strain hardening, and those where member buckling effects are more significant). The Rasmussen and Rondal [21] predictions cannot be calculated for all of the collected literature data, as it requires compressive material properties which are rarely reported. This design method has also been applied using tensile material properties, although the strain hardening exponent $n$ is not always provided in the literature and hence, where required, the proposals for $n$ by Arrayago et al. [52] have been used.

Overall it can be seen that the predictions of the Young and Ellobody [22] and Ellobody and Young [23] buckling curves are the most conservative of the design proposals considered for the austenitic and ferritic datasets, as seen in Figures 22 and 24. The proposals by Rasmussen and Rondal 21] provide predictions that are generally the closest on average to the measured ultimate compressive capacities using both compressive and tensile material properties, as seen in Table 13, although there are a number of predictions for the duplex and ferritic stainless steel columns on the unsafe side, as shown in Figures 23 and 24 respectively. The Rasmussen and Rondal [21] predictions using the compressive material properties, with the smaller dataset against which to evaluate the proposal, are the most consistent with the lowest COV value. The Theofanous et al. 25] proposal and the new flexural buckling curve proposed herein predict intermediate resistances between Young and Ellobody [22] and Ellobody and Young [23], and Rasmussen and Rondal [21] for the austenitic and ferritic datasets. On average the new proposed curve provides estimates of the ultimate compressive 


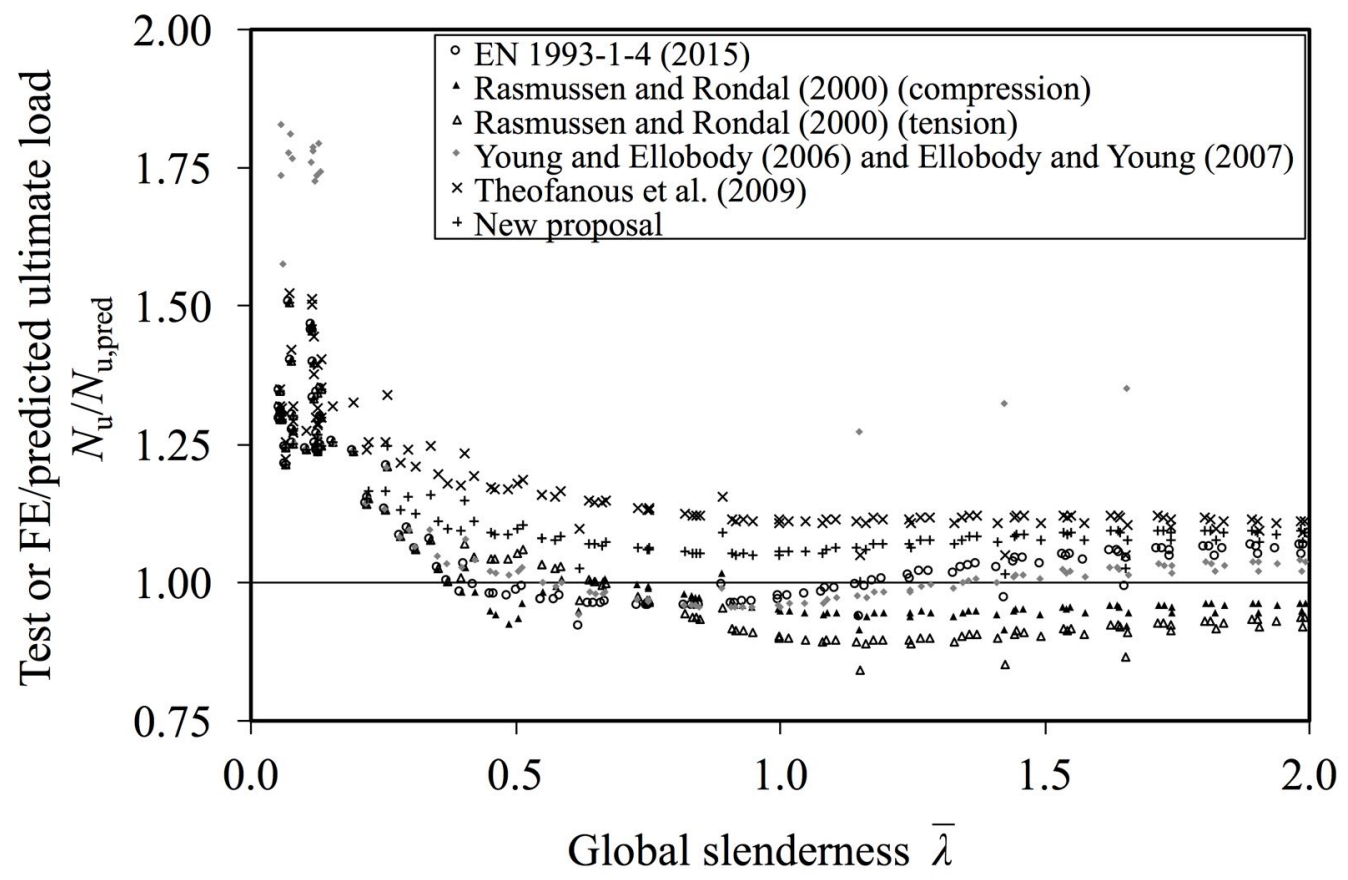

Figure 23: Comparisons of design provisions with experimental and numerical data for duplex stainless steel CHS columns

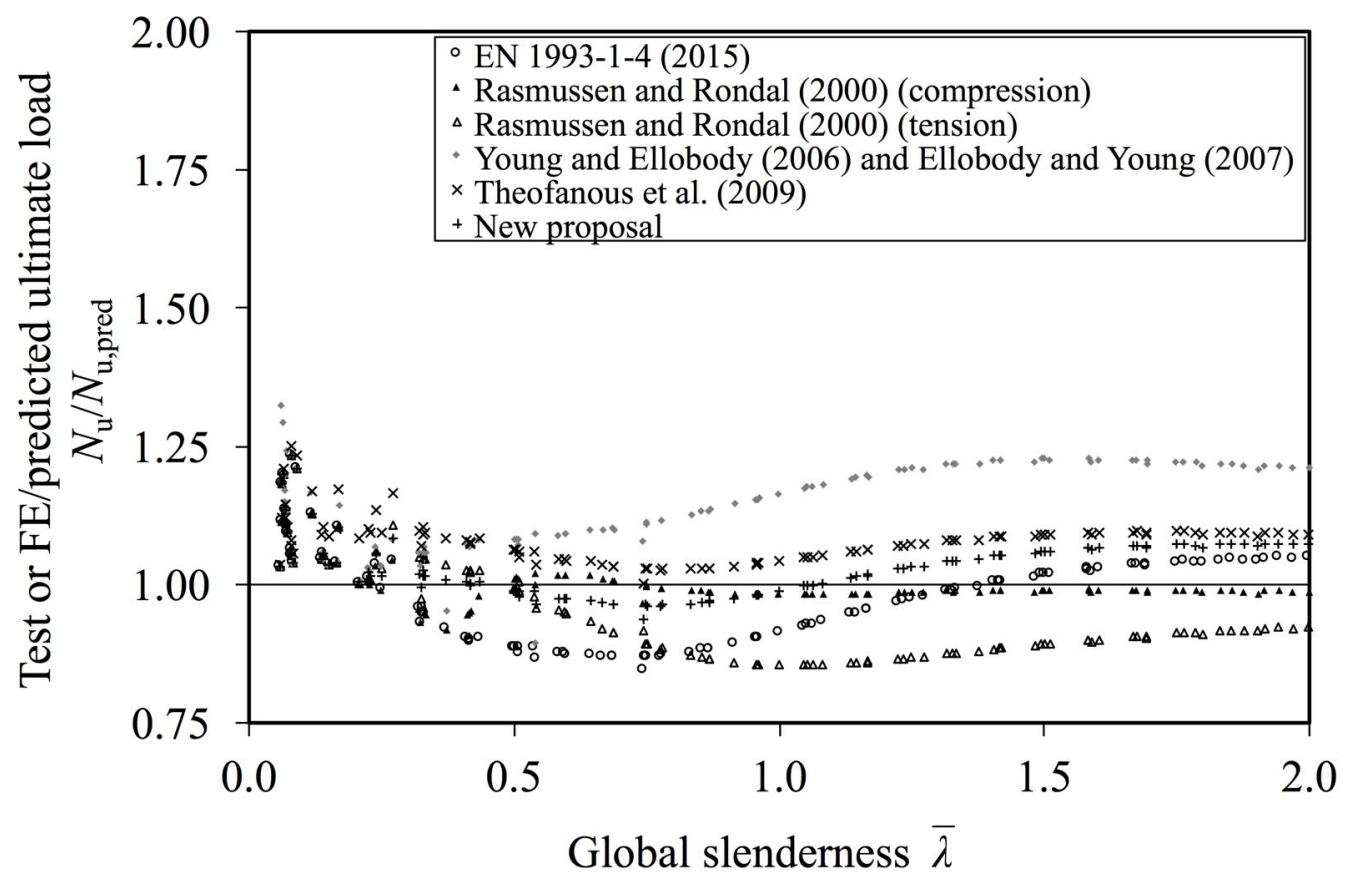

Figure 24: Comparisons of design provisions with experimental and numerical data for ferritic stainless steel CHS columns 


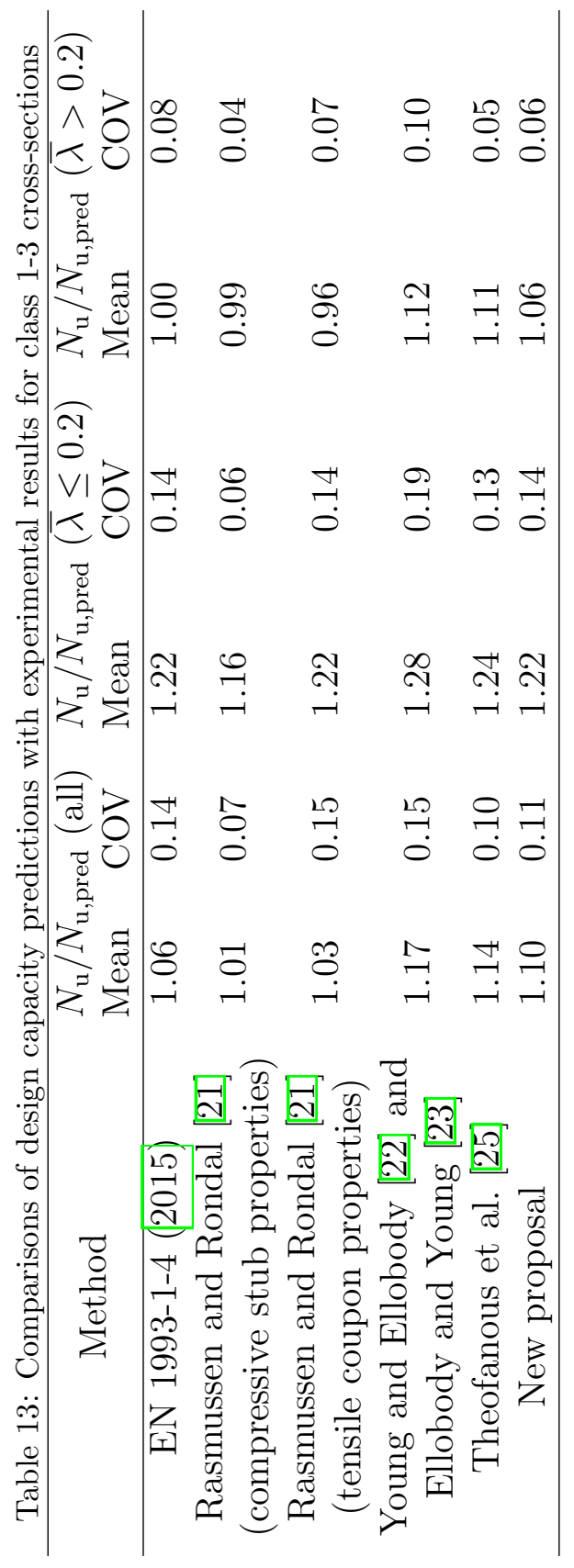


capacity that are closer to the experimental and numerical results than the Theofanous et al. [25] proposal, as shown in Table 13 and Figures 22, 24.

\section{Reliability analyses}

Design standards utilise partial factors on actions and resistance such that structures are designed with an appropriate level of reliability. In the European design standards, the member level resistance prediction is divided by a partial factor $\gamma_{\mathrm{M} 1}$, as seen in Equations 7 and 8 , to ensure that structures are designed with an appropriate level of reliability. The partial factors are determined using a procedure outlined in Annex D of EN 1990 (2005); this incorporates the variation of the material and geometric properties, the resistance model and the number of test results used in the evaluation of the model [53, 54]. At the present time $\gamma_{\mathrm{M} 1}=1.1$ in EN 1993-1-4 (2015).

The reliability analyses were initially undertaken on the CHS columns with class 1-3 crosssections and $\bar{\lambda} \geq \bar{\lambda}_{0}$ in order to isolate the global buckling. The focus was therefore on cases where $\chi \leq 1$.

The current partial factors in EN 1993-1-4 (2015) are based on experiments undertaken in the 1990s and earlier, and it has been noted that since then, production techniques have improved and the stainless steel experimental dataset has significantly increased in size [53]. Afshan et al. [54 undertook an extensive re-evaluation of the EN 1993-1-4 (2015) partial factors and noted that the current CHS flexural buckling guidance is inappropriate for the adopted member level partial factor $\gamma_{\mathrm{M} 1}=1.1$, although at the time only a limited dataset was available. The new experimental and numerical dataset produced in this study has been used to reassess the $\gamma_{\mathrm{M} 1}$ partial factor with the current stainless steel hollow section buckling curve in EN 1993-1-4 (2015) as summarised in Table 14, where $n$ is the size of the dataset, the over-strength factor is the mean yield strength normalised by the nominal yield strength, $V_{f_{\mathrm{y}}}$ is the coefficient of variation of the yield strength, $V_{\text {geometry }}$ is the coefficient of variation of the geometry of the cross-section, $k_{\mathrm{d}, \mathrm{n}}$ is the fractile factor and is related to the size of the dataset, $b$ is the average ratio of the experimental or numerical resistance to model resistance and $V_{\delta}$ is the coefficient of variation of the tests relative to the resistance model. The over-strength factors, $V_{f_{\mathrm{y}}}$ and $V_{\text {geometry }}$ used in the reliability analysis were taken from Afshan et al. [54]. The least squares approach from Annex D of EN 1990 (2005) is not used for the calculation of the $b$ parameter as this is deemed to bias the value towards the results with higher failure loads. It is apparent that with a larger experimental and numerical dataset the $\gamma_{\mathrm{M} 1}$ partial factor for the current EN 1993-1-4 (2015) flexural buckling curve should still be increased, although to a lower value than the analysis by Afshan et al. [54] suggested.

The required $\gamma_{\mathrm{M} 1}$ partial factor for the Theofanous et al. [25] and new proposed buckling curve has been evaluated using the new experimental and numerical dataset, with the results 
summarised in Tables 15 and 16 respectively. The new proposed buckling curve has a lower average ratio of the experimental or numerical resistance to model resistance $b$ across the austenitic, duplex and ferritic datasets and is less scattered in terms of $V_{\delta}$ for the austenitic and duplex datasets, and slightly more scattered for the ferritic data, compared with the Theofanous et al. 25 buckling curve. The Theofanous et al. 25 buckling curve predictions typically have a higher $V_{\delta}$ compared with the EN 1993-1-4 (2015) flexural buckling curve, which can be attributed to the very short $\chi=1$ plateau. The high $V_{\delta}$, and subsequent larger $\gamma_{\mathrm{M} 1}$ partial factor, for the experimental austenitic dataset in Tables 15 and 16 can be attributed to the dataset scatter as apparent from Figure 19, rather than a less optimal design curve. The $\gamma_{\mathrm{M} 1}$ partial factors for the new proposal are closer to the current EN 1993-1-4 (2015) value of $\gamma_{\mathrm{M} 1}=1.1$ than the current codified flexural buckling curve and less conservative than the Theofanous et al. [25] $\gamma_{\mathrm{M} 1}$ partial factors for the duplex and ferritic datasets. For the class 4 stainless steel CHS, the $\gamma_{\mathrm{M} 1}$ partial factors for the new proposal are 1.04, 1.15 and 1.08, for the experimental and numerical austenitic, duplex and ferritic datasets respectively, and therefore the proposal is also generally applicable to slender stainless steel cold-formed CHS columns. Overall, the new proposed flexural buckling curve achieves approximately the required level of reliability in its flexural buckling capacity predictions.

\section{Conclusions}

A comprehensive experimental investigation focusing upon concentrically loaded austenitic, duplex and ferritic stainless steel cold-formed circular hollow section columns has been undertaken. The programme consisted of material property tests, stub column tests and column member tests on non-slender class 1 to slender class 4 cross-sections. Additional data were produced using validated finite element simulations. The experimental and numerical results have been compared against the current European design guidance and it was observed, similar to previous studies, that the current design approach can be unconservative. Existing non-iterative design proposals were then evaluated and were generally found to offer improved predictions of member level resistance. Following analysis of the assembled dataset, a new buckling curve for cold-formed stainless steel CHS columns, of the same form as the existing EN 1993-1-4 (2015) curve, was proposed, with the same imperfection factor $\alpha=0.49$ as the current code but with a reduced limiting slenderness $\bar{\lambda}_{0}=0.20$, with the aim of offering safe, but efficient predictions, and a design approach that is not overly onerous to undertake. Reliability analyses were undertaken on the existing EN 1993-1-4 (2015) flexural buckling curve, where it was seen that to achieve the required level of reliability in the member level resistance a partial safety factor larger than that currently utilised is required. Similar analyses were performed on the new proposed buckling curve, where it was shown that the current partial safety factor $\gamma_{\mathrm{M} 1}=1.1$ is appropriate. 

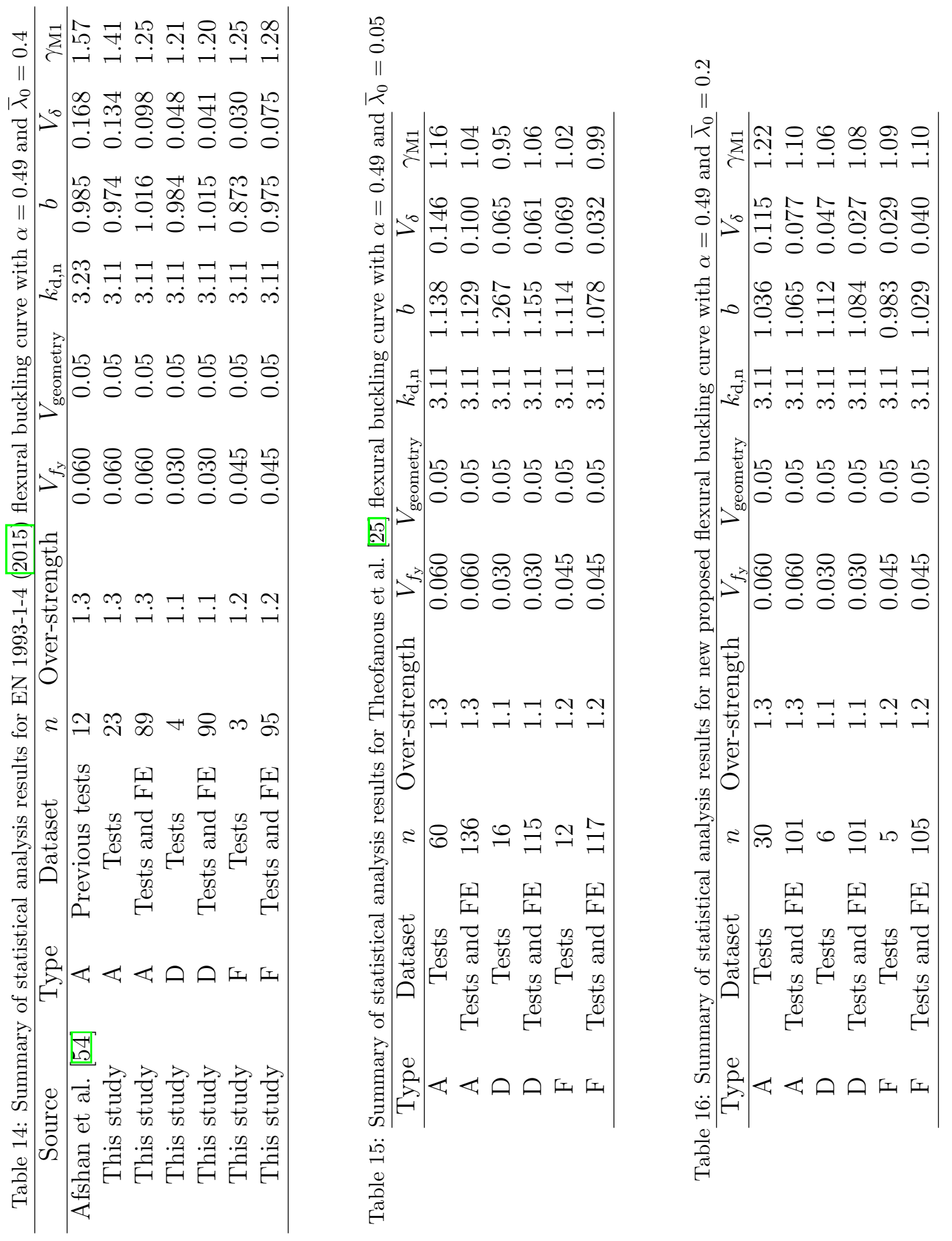


\section{Acknowledgements}

This experimental programme was possible thanks to funding and support from the Outokumpu Research Foundation, Engineering and Physical Sciences Research Council (EPSRC), Ministerio de Economía y Competitividad (Spanish Ministry of Economics and Competitiveness) under the Project BIA 2012-36373 and an Erasmus+ Traineeship grant. The authors would like to acknowledge the contribution of Gordon Herbert, Alfredo Olivo, Hayden Spektor and Joel Thomas at Imperial College London and Tomás García, Jordi Lafuente, Jordi Cabrerizo and Itsaso Arrayago at Universitat Politècnica de Catalunya. The authors would also like to thank Rolando Chacón and Enrique Mirambell for their support during the experimental programme at Universitat Politècnica de Catalunya.

\section{References}

[1] European Committee for Standardisation . BS EN 1990:2002+A1:2005 Eurocode - basis of structural design. 2005. ISBN 978058062664 7. doi:10.1680/cien.144.6.8.40609.

[2] Dutta D. Structures with hollow sections. Weinheim: Wiley VCH; 2002.

[3] Gardner L. The use of stainless steel in structures. Progress in Structural Engineering and Materials 2005; $7(2): 45-55$. doi $10.1002 /$ pse. 190

[4] European Committee for Standardisation . EN 1993-1-4:2006+A1:2015 Eurocode 3 - design of steel structures - part 1-4: general rules - supplementary rules for stainless steel. 2015.

[5] International Stainless Steel Forum . The ferritic solution. 2007.

[6] European Committee for Standardisation . EN 1993-1-1:2005+A1:2014 Eurocode 3: design of steel structures - part 1-1: general rules and rules for buildings. 2014.

[7] Rasmussen KJR, Hancock GJ. Design of cold-formed stainless steel tubular members. I: columns. Journal of Structural Engineering ASCE 1993;119(8):2349-67.

[8] Talja A. Test report on welded I and CHS beams, columns and beam-columns. Report to ECSC VTT Building Technology, Finland 1997;

[9] Burgan BA, Baddoo NR, Gilsenan KA. Structural design of stainless steel members - comparison between Eurocode 3, Part 1.4 and test results. Journal of Constructional Steel Research 2000;54(1):51-73. doi: $10.1016 /$ S0143-974X(99)00055-3.

[10] Rasmussen KJR. Recent research on stainless steel tubular structures. Journal of Constructional Steel Research 2000;54(1):75-88.

[11] Young B, Hartono W. Compression tests of stainless steel tubular members. Journal of Structural Engineering ASCE 2002;128(6):754-61. doi:10.1061/(ASCE) 0733-9445(2002) 128:6(754).

[12] Kuwamura H. Local buckling of thin-walled stainless steel members. Steel Structures 2003;3:191-201.

[13] Gardner L, Nethercot DA. Experiments on stainless steel hollow sections - part 1: material and cross-sectional behaviour. Journal of Constructional Steel Research 2004;60(9):1291-318. doi:10.1016/ j.jcsr.2003.11.006.

[14] Lam D, Gardner L. Structural design of stainless steel concrete filled columns. Journal of Constructional Steel Research 2008;64(11):1275-82. doi:10.1016/j.jcsr.2008.04.012.

[15] Uy B, Tao Z, Han LH. Behaviour of short and slender concrete-filled stainless steel tubular columns. Journal of Constructional Steel Research 2011;67(3):360-78. doi:10.1016/j.jcsr.2010.10.004.

[16] Zhao O, Gardner L, Young B. Structural performance of stainless steel circular hollow sections under combined axial load and bending - part 1: experiments and numerical modelling. Thin-Walled Structures 2015;101:231-9. doi:10.1016/j.tws.2015.12.003.

[17] Zhao O, Gardner L, Young B. Testing and numerical modelling of austenitic stainless steel CHS beam-columns. Engineering Structures 2016;111:263-74. doi 10.1017/CB09781107415324.004. arXiv:arXiv:1011.1669v3. 
[18] Bardi FC, Kyriakides S. Plastic buckling of circular tubes under axial compression - part I: experiments. International Journal of Mechanical Sciences 2006;48(8):830-41. doi:10.1016/j.ijmecsci.2006.03 005 .

[19] Paquette JA, Kyriakides S. Plastic buckling of tubes under axial compression and internal pressure. International Journal of Mechanical Sciences 2006;48(8):855-67. doi:10.1016/j.ijmecsci.2006.03 003.

[20] Stangenberg H. Report to the ECSC - draft final report ferritic stainless steels. Tech. Rep.; RWTH; 2000.

[21] Rasmussen KJR, Rondal J. Column curves for stainless steel alloys. Journal of Constructional Steel Research 2000;54:89-107. doi:10.1016/S0143-974X(99)00095-4.

[22] Young B, Ellobody E. Column design of cold-formed stainless steel slender circular hollow sections. Steel and Composite Structures 2006;6(4):285-302.

[23] Ellobody E, Young B. Investigation of cold-formed stainless steel non-slender circular hollow section columns. Steel and Composite Structures 2007;7(4):321-37.

[24] Ashraf M, Gardner L, Nethercot DA. Resistance of stainless steel CHS columns based on cross-section deformation capacity. Journal of Constructional Steel Research 2008;64(9):962-70. doi:10.1016/j jcsr.2007.10.010.

[25] Theofanous M, Chan TM, Gardner L. Structural response of stainless steel oval hollow section compression members. Engineering Structures 2009;31(4):922-34. doi:10.1016/j.engstruct.2008.12 002

[26] Shu G, Zheng B, Xin L. A new design method for stainless steel columns subjected to flexural buckling. Thin-Walled Structures 2014;83:43-51. doi 10.1016/j.tws.2014.01.018.

[27] Afshan S, Rossi B, Gardner L. Strength enhancements in cold-formed structural sections - part I: material testing. Journal of Constructional Steel Research 2013;83:177-88. doi $10.1016 /$ j.jcsr.2012.12.008.

[28] European Committee for Standardisation . BS EN ISO 6892-1:2009 metallic materials - tensile testing part 1: method of test at ambient temperature. 2009.

[29] Ramberg W, Osgood WR. Description of stress-strain curves by three parameters. 1943. ISBN NACA-TN-902.

[30] Mirambell E, Real E. On the calculation of deflections in structural stainless steel beams: an experimental and numerical investigation. Journal of Constructional Steel Research 2000;54(1):109-33. doi 10.1016/ S0143-974X (99)00051-6

[31] Rasmussen KJR. Full-range stress-strain curves for stainless steel alloys. Journal of Constructional Steel Research 2003;59(2003):47-61.

[32] Gardner L, Ashraf M. Structural design for non-linear metallic materials. Engineering Structures 2006;28(6):926-34. doi:10.1016/j.engstruct.2005.11.001.

[33] European Committee for Standardisation . BS EN 10219-2:2006 Cold formed welded structural hollow sections of non-alloy and fine grain steels. Part 2: tolerances, dimensions and sectional properties; vol. 3. 2006.

[34] Ziemian R. Guide to Stability Design Criteria for Metal Structures. 6th ed.; New York: John Wiley \& Sons, Inc.; 2010.

[35] Centre for Advanced Structural Engineering . Compression tests of stainless steel tubular columns. Investigation report S770. 1990.

[36] British Standards Institution . BS 5950-1:2000 structural use of steelwork in building - part 1: code of practice for design - rolled and welded sections. 2000.

[37] Chan TM, Gardner L. Compressive resistance of hot-rolled elliptical hollow sections. Engineering Structures 2008;30(2):522-32. doi 10.1016/j.engstruct.2007.04.019.

[38] Buchanan C, Gardner L, Liew A. The continuous strength method for the design of circular hollow sections. Journal of Constructional Steel Research 2016;118:207-16. doi:10.1016/j.jcsr.2015.11.006

[39] Huang Y, Young B. Experimental investigation of cold-formed lean duplex stainless steel beam-columns. Thin-Walled Structures 2014;76:105-17. doi:10.1016/j.tws.2013.11.006.

[40] Zhao O, Rossi B, Gardner L, Young B. Behaviour of structural stainless steel cross-sections under 
combined loading - part I: experimental study. Engineering Structures 2015;89:236-46. doi:10.1016/j engstruct.2014.11.014.

[41] Dassault Systèmes Simulia Corp. . Abaqus/CAE 2016. 2015.

[42] Gardner L, Nethercot DA. Numerical modeling of stainless steel structural components - a consistent approach. Journal of Structural Engineering ASCE 2004;130(10):1586-601. doi:10.1061/(ASCE) 0733-9445(2004) 130:10(1586).

[43] Silvestre N. Generalised beam theory to analyse the buckling behaviour of circular cylindrical shells and tubes. Thin-Walled Structures 2007;45(2):185-98. doi:10.1016/j.tws.2007.02.001.

[44] Rotter JM, Sadowski AJ, Chen L. Nonlinear stability of thin elastic cylinders of different length under global bending. International Journal of Solids and Structures 2014;51(15-16):2826-39. doi:10.1016/j ijsolstr.2014.04.002

[45] Buchanan C. Testing and design of conventional and novel stainless steel hollow structural sections. Ph.D. thesis; Imperial College London; 2017.

[46] Zhao O, Gardner L, Young B. Structural performance of stainless steel circular hollow sections under combined axial load and bending - part 2: parametric studies and design. Thin-Walled Structures 2015;101:240-8. doi:10.1016/j.tws.2015.12.005.

[47] Cruise RB, Gardner L. Residual stress analysis of structural stainless steel sections. Journal of Constructional Steel Research 2008;64(3):352-66. doi:10.1016/j.jcsr.2007.08.001.

[48] Jandera M, Gardner L, Machacek J. Residual stresses in cold-rolled stainless steel hollow sections. Journal of Constructional Steel Research 2008;64(11):1255-63. doi 10.1016/j.jcsr.2008.07.022.

[49] Hradil P, Fülöp L, Talja A. Global stability of thin-walled ferritic stainless steel members. Thin-Walled Structures 2012;61:106-14. doi $10.1016 / j$.tws.2012.05.006.

[50] Ayrton WE, Perry J. On struts. The Engineer 1886;62:464-465 and 513.

[51] Rasmussen KJR, Rondal J. Strength curves for metal columns. Journal of Structural Engineering ASCE 1997;123(6):721-8.

[52] Arrayago I, Real E, Gardner L. Description of stress-strain curves for stainless steel alloys. Materials \& Design 2015;87:540-52. doi 10.1016/j.matdes.2015.08.001.

[53] Baddoo N. 100 years of stainless steel: a review of structural applications and the development of design rules. The Structural Engineer 2013;91(8):10-8.

[54] Afshan S, Francis P, Baddoo NR, Gardner L. Reliability analysis of structural stainless steel design provisions. Journal of Constructional Steel Research 2015;114:293-304. 